\title{
A Influência da Dinâmica Eleitoral sobre 0 Comportamento dos Partidos na Câmara dos Deputados e no Senado Federal*
}

\author{
Geralda Luiza de Miranda
}

\section{INTRODUÇÃO}

$\mathrm{D}$ iversos estudos têm salientado os efeitos perversos do presidencialismo sobre o comportamento dos partidos e as relações entre os poderes. Indisciplina, instabilidade, paralisia decisória e diferença de propósitos entre Executivo e Legislativo são alguns desses efeitos. Os problemas teriam origem especialmente no fato de as eleições serem separadas e os mandatos, rígidos. No parlamentarismo, mecanismos como o voto de confiança e o controle da agenda pelo chefe do Exe-

\footnotetext{
* Este artigo foi extraído de minha tese, O Comportamento dos Partidos na Câmara dos Deputados e no Senado Federal (1991-2007), defendida junto ao Departamento de Ciência Política (DCP) da Faculdade de Filosofia e Ciências Humanas (FAFICH) da Universidade Federal de Minas Gerais (UFMG) em 2008. Reflete a orientação cuidadosa de Carlos Ranulfo e as críticas dos professores da banca de defesa: Argelina Figueiredo, Jairo Nicolau, Magna Inácio e Fábio Wanderley. A elaboração da tese foi facilitada pelas bolsas do Conselho Nacional de Desenvolvimento Científico e Tecnológico (CNPq) e da (Capes), bem como pelo apoio de amigos, especialmente Felipe Nunes, e de diversos analistas que me forneceram dados de organização trabalhosa: Figueiredo e Limongi (bancos de dados legislativos da Câmara e do Senado), André Marenco (tempo de filiação dos deputados) e Rogério Schmitt (coligações de 1990). Lucio Rennó, Fabiano Santos e outros participantes do Grupo de Trabalho Estudos Legislativos, no $32^{\circ}$ Encontro da Associação Nacional de Pós-Graduação e Pesquisa em Ciências Sociais (Anpocs), fizeram importantes observações a uma versão preliminar. Agradeço a todos. Agradeço também aos pareceristas anônimos da revista $D A D O S$ os valiosos questionamentos e sugestões. Os equívocos remanescentes são de minha responsabilidade.
}

DADOS - Revista de Ciências Sociais, Rio de Janeiro, Vol. 52, n-4, 2009, pp. 911 a 959. 
cutivo configurariam uma "fusão" dos poderes, o que estimularia a cooperação e facilitaria a governabilidade.

As análises sobre o comportamento dos parlamentares brasileiros, realizadas a partir das premissas acima, apontam para um quadro desolador. Os políticos, de acordo com Sartori (1994), relacionam-se com os partidos como se eles fossem "de aluguel". A busca de apoio pelo presidente, por meio da distribuição de pastas ministeriais, não garante, segundo o autor, nenhuma promessa do ponto de vista estrutural ou sistêmico. Para Jones (1995), as instituições brasileiras estimulam a resistência do presidente em ceder poder à oposição e o interesse desta no fracasso do governo. Linz (1991), como Jones, afirma que os partidos derrotados na eleição não apoiam o presidente e trabalham para seu fracasso.

Os problemas seriam especialmente sérios pelo fato de o presidencialismo brasileiro estar combinado com o federalismo, sistema eleitoral proporcional com lista aberta e distritos de grande magnitude (Ames, 2003; Mainwaring, 1999; Samuels, 2003; Lijphart, 1991; Shugart e Carey, 1992). Para Lijphart, essa combinação resulta em governos minoritários e abre a possibilidade de que os partidos que controlam o Executivo e o Legislativo ocupem posições contrárias no espectro ideológico. Segundo Mainwaring, essa combinação estimula a fragmentação do sistema partidário, o paroquialismo na formulação de políticas, mandatos personalizados, partidos marcados por faccionalismo e indisciplina, migração partidária e formação de coalizões de governo ad hoc pela ampla utilização de patronagem.

Figueiredo e Limongi, a partir de meados da década de 1990, propõem uma perspectiva de análise do sistema brasileiro que se distancia desses estudos. Pesquisando a dinâmica legislativa do período pós-constitucional, os autores constatam um padrão ideologicamente consistente de coalizões governativas, disciplina parlamentar e altas taxas de sucesso e dominância do Executivo no processo legislativo. O quadro é atribuído às prerrogativas constitucionais do Executivo e, a exemplo dos estudos de Kiewiet e McCubbins (1991) e de Cox e McCubbins (1993), às prerrogativas regimentais das lideranças partidárias. A influência da centralização do processo decisório nas mãos desses dois atores, sobre o comportamento parlamentar, ocorre, de acordo com Figueiredo e Limongi, da seguinte maneira: 
O controle de agenda exercido pelos líderes partidários e pelo Executivo reduz as chances de sucesso das iniciativas individuais dos deputados. Reduz também a possibilidade de que deputados adotem estratégias do tipofree-rider. Não porque inexistam os incentivos para sua adoção ou porque os deputados tenham assimilado normas contrárias a esse tipo de estratégia. Os líderes são capazes de reduzir as oportunidades para o comportamento individualista e oportunista (1999:10).

A literatura posterior ao trabalho de Figueiredo e Limongi tem reforçado a influência da centralização do processo decisório sobre o comportamento parlamentar e a dinâmica entre os poderes, e acrescentado outras variáveis. Amorim Neto, Cox e McCubbins (2003) salientam a influência da proporcionalidade entre as pastas ministeriais distribuídas e o tamanho dos partidos sobre a disciplina. Santos (2002) argumenta que o alinhamento dos partidos ao governo propicia economia de informações ao eleitor e, por isso, incentiva a disciplina nas votações dos projetos do presidente. $\mathrm{O}$ autor ressalta também que a distribuição de cargos e de recursos orçamentários pelo Executivo influencia a disciplina (Santos, 1997; 1999). Fatores suprapartidários, como magnitude, abrangência e contiguidade ideológica das coalizões, são indicados por Inácio (2006) e Marcus Melo (2007) como capazes de também influenciar a produção legislativa e o comportamento partidário.

Em comum, esses estudos apontam para a importância dos partidos na dinâmica legislativa. A referência analítica permanece sendo o modelo partidário (Kiewiet e McCubbins, 1991; Cox e McCubbins, 1993), adaptado para o sistema brasileiro com a incorporação das prerrogativas constitucionais do Executivo. A conclusão, em termos gerais, é que a centralização do poder nas lideranças e no Executivo reduz ou coíbe os estímulos distributivistas ou paroquialistas, gerados pelo formato do sistema eleitoral.

Outros estudos indicam, na dinâmica decisória brasileira, a coexistência de estímulos comportamentais diversos (Ames, 2003; Amorim Neto e Santos, 2003; Carvalho, 2003; Pereira e Mueller, 2003; Pereira e Rennó, 2001). Apesar de ressaltarem a influência da centralização do processo decisório, esses estudos argumentam que fatores relacionados à arena eleitoral influenciam a dinâmica parlamentar; por exemplo, o tipo de base eleitoral dos deputados. Os achados indicam que a produção e o comportamento legislativos combinam aspectos partidá- 
rios e distributivistas ou paroquialistas. Contrapondo-se às análises que salientam o partidarismo, o argumento é que a centralização do processo decisório não logra anular significativamente os incentivos gerados na arena eleitoral.

Neste artigo, analiso o comportamento dos partidos na Câmara dos Deputados e no Senado Federal. O objetivo é explicar a variação em seu comportamento nas votações nominais. Como nos estudos apresentados, também parto do pressuposto de que esse comportamento, em relação ao que vigorou no período de 1946 a 1964, é influenciado pela centralização do processo decisório. Questiono, no entanto, o argumento, muitas vezes não explicitado, de que o partidarismo do comportamento parlamentar, especialmente a disciplina, ocorre à revelia ou independentemente dos incentivos que emergem da arena eleitoral, resultando tão somente da organização do processo decisório. A análise se sustenta, em termos teóricos, nos estudos de Cox (1987), Kiewiet e McCubbins (1991), Shugart e Carey (1992), Cox e McCubbins (1993) e Powell Jr. (2000), que buscam explicações para o comportamento parlamentar em fatores exógenos à arena decisória, mais especificamente na eficiência das eleições e em seus efeitos sobre a accountability eleitoral.

Na primeira parte, discuto as condições institucionais que possibilitam a emergência da eficiência e sua relação com a accountability. Verifico, na sequência, que as eleições presidenciais brasileiras adquiriram, a partir de 1994, um grau significativo de eficiência, influenciando o desempenho eleitoral dos principais partidos competidores pelo cargo presidencial e suas estratégias coligacionistas nas eleições congressuais e para as governadorias. A partir disso, argumento que a eficiência das disputas presidenciais, ao influenciar o desempenho congressual dos partidos que dela participam reiteradamente, estimula-os a coordenarem mais seu comportamento parlamentar, o que não é esperado dos outros partidos. Isso significa que, em um sistema multipartidário, o tipo de posicionamento dos partidos nas eleições presidenciais pode traduzir-se em estratégias diferentes das lideranças, na arena parlamentar, e em diferentes disposições das bancadas partidárias diante do Executivo e dos líderes, conformando, assim, partidos centralizados ou descentralizados.

As hipóteses são testadas na segunda parte. No que se refere aos líderes, são analisadas a coordenação que eles exercem sobre o comporta- 
mento das bancadas e a coerência que mantêm entre posicionamento eleitoral e posicionamento diante do governo. No que se refere às bancadas, é analisada sua disciplina. Nos testes, o comportamento dos líderes e das bancadas é relacionado aos fatores vinculados à dinâmica das eleições e ao posicionamento diante do governo. Na tentativa de controlar os efeitos sobre a disciplina de uma variável que antecede a própria inserção dos partidos na arena eleitoral - o tipo de organização partidária -, insiro, nos testes, uma variável destinada a diferenciar organizações mais coesas das menos coesas: o tempo de filiação à organização partidária.

\section{EFICIÊNCIA E ACCOUNTABILITY: A INFLUÊNCIA DAS DISPUTAS PRESIDENCIAIS SOBRE A DINÂMICA ELEITORAL CONGRESSUAL}

Nas análises sobre o comportamento dos partidos, fazem-se duas distinções importantes: uma em torno da representação e outra em torno das eleições. Ambas se fundam no pressuposto de que é nas eleições que se forjam as conexões entre os representantes e os eleitores, e é a partir dessas conexões que emergem os incentivos comportamentais fornecidos pelos últimos aos primeiros. Nesse sentido, como diz Powell Jr. (2000), as eleições são a forma por meio da qual os eleitores "formatam" o processo político.

A representação pode ser paroquialista ou nacional/geral. Esta se relaciona aos interesses de uma constituency nacional; a primeira, aos interesses de grupos distrital ou regionalmente localizados e, conforme Shugart e Carey (1992), aos interesses ideológicos ou políticos de setores sociais específicos, como classes sociais, grupos étnicos ou religiosos, estejam ou não geograficamente localizados. Eleições eficientes seriam aquelas em que os partidos apresentam aos eleitores propostas de políticas nacionais alternativas, permitindo-lhes uma identificação clara e um controle efetivo do desempenho governamental; eleições representativas, as que possibilitam a expressão da diversidade de interesses na assembleia. Um sistema eleitoral que maximizasse a representatividade ofereceria a cada eleitor um partido situado próximo a seu ponto ideal de políticas, mas não a identificabilidade de duas opções competitivas de governo, não lhe capacitando, portanto, para o controle de seu desempenho (Cox, 1987; Powell Jr., 2000; Shugart e Carey, 1992). 
Historicamente, de acordo com Cox (1987), sistemas com eleições eficientes se desenvolveram na Inglaterra. Partidos e candidatos, em virtude da dependência prática do governo do voto de confiança da assembleia, teriam adquirido incentivos para conduzir as campanhas em torno de políticas nacionais. Powell Jr. (2000), pesquisando um número maior de sistemas, inclusive presidencialistas, constata variabilidade quanto ao tipo de eleições e aponta um trade-off entre eficiência e representatividade: sistemas eficientes, especificamente os majoritários, seriam menos representativos da diversidade; os que possibilitam maior representatividade, ou seja, os proporcionais, dificilmente produziriam eficiência e capacitariam em menor medida os eleitores para a $a c$ countability. No entanto, para o autor, mesmo possibilitando certo grau de representatividade, os sistemas parlamentaristas seriam mais propensos a produzir eficiência que os presidencialistas.

Distinções e conclusões semelhantes são elaboradas por Shugart e Carey (1992) a propósito dos sistemas presidencialistas. Nesses sistemas, entretanto, em virtude das eleições separadas, haveria mais opções, podendo-se atender aos dois desideratos simultaneamente. Dependendo do tipo e do número efetivo de partidos, tanto a eficiência pode emergir na eleição legislativa, embora sempre em menor medida que no parlamentarismo, quanto pode ser difícil distinguir alternativas de políticas na campanha presidencial.

O número de partidos seria influenciado pelo tipo de sistema eleitoral e pelo ciclo das eleições presidenciais e congressuais. A tese pode ser assim sintetizada: eleições concomitantes e por pluralidade reduzem o número de partidos, possibilitando eficiência em ambas; eleições concorrentes, sendo a presidencial por pluralidade e a congressual proporcional, teriam como efeito a influência da primeira sobre a segunda, embora mantendo a possibilidade de certa representatividade. Um maior número de partidos, na eleição para assembleia, resultaria do incentivo às lideranças para aumentar seu poder de barganha na posterior distribuição de cargos, pois a maior visibilidade da disputa presidencial favoreceria o desempenho eleitoral dos partidos. O incentivo à multiplicação dos partidos e à desvinculação das campanhas executivas e congressuais seria ampliado quando as eleições são não concomitantes ou quando a eleição presidencial é em dois turnos. A perspectiva de um segundo turno desestimularia os partidos a estabelecerem acordos no primeiro, com vistas a aumentar seu poder de barganha nas negociações de composição do governo. Empiricamente, de acordo 
com Shugart e Carey, essas combinações desencorajam a consolidação de políticas nacionais e incentivam a fragmentação do sistema partidário, ou seja, coíbem a eficiência.

É importante salientar que, nos sistemas eficientes, um comportamento parlamentar mais coordenado, evidenciado especialmente pela disciplina, é estimulado pelo maior valor eleitoral da legenda partidária, ou seja, pela possibilidade de os eleitores identificarem claramente os partidos que vão governar e avaliarem facilmente seu desempenho. Nesse sentido, o argumento é fundamentalmente diferente do que é desenvolvido por Samuels e Eaton (2002) e Samuels (2003). De acordo com esses autores, nos sistemas presidencialistas, a disciplina e a responsabilização dos partidos pelo governo podem ser estimuladas pelo presidential coattail effects. Nesse caso, haveria convergência entre as propostas apresentadas na campanha presidencial e aquelas apresentadas pelas diversas elites partidárias (regionais ou locais) na disputa legislativa. Nas eleições eficientes, também se prevê essa convergência, mas a possibilidade de os partidos perdedores se alinharem ao governo é significativamente menor, pois eles possuem interesses de longo prazo e não estão dispostos a se responsabilizar por um governo que não elegeram.

A mesma coordenação da ação parlamentar, prevista nos sistemas eficientes e naqueles em que há contágio da eleição presidencial, está relacionada, no sistema norte-americano, de acordo com Kiewiet e McCubbins (1991) e Cox e McCubbins (1993; 1995), à delegação de prerrogativas legislativas aos líderes. Nesse sistema, no entanto, essa delegação, de acordo com os autores, esteve condicionada à superação das divergências que dividiam os partidos na arena eleitoral. Contudo, seu objetivo é o mesmo: imprimir visibilidade nacional à legenda partidária tendo em vista a accountability eleitoral.

Apresentadas essas teses, uma rápida avaliação dos principais diagnósticos sobre o sistema partidário, os partidos e as eleições permite uma melhor aproximação da dinâmica atual.

\section{Diagnósticos sobre o Sistema Partidário e as Eleições no Brasil}

Os diagnósticos sobre o sistema partidário brasileiro têm sido marcadamente negativos. Deparando-se com partidos organizacionalmente fracos e sem enraizamento social, Lamounier e Meneguello (1986) classificam o sistema como um "caso notório de subdesenvolvimento par- 
tidário". O diagnóstico de Lima Júnior (1993:151) é semelhante: “O país não dispõe ainda de um sistema partidário nacional". A fragmentação, a alta volatilidade e a distribuição desigual da votação dos partidos entre os estados também sustentam os diagnósticos de Mainwaring (1999) e Mainwaring e Jones (2003) de baixa institucionalização e de nacionalização do sistema partidário.

As evidências são fortes. O sistema bipartidário, que surgiu com a legislação de 1965, começa a ser desconstituído nas eleições de 1982, quando surgem PT $^{*}$, PDT e uma nova versão do PTB. Em 1986, surgem (ou ressurgem) outros partidos: PCB, PC do B, PSB, PLe PDC. Ainda na década de 1980, surge outro grupo de partidos a partir de cisões nos já existentes: o PFL foi criado em 1985, com a divisão do PDS; o PSDB, em 1988, por membros da esquerda do PMDB. Assim, a fragmentação do sistema foi abrupta (Lima Júnior, 1993). O número efetivo de partidos (Ne) passou de 2,4 e 2,8, nas eleições de 1982 e 1986, respectivamente, para 8,$7 ; 8,2 ; 7,1 ; 8,5 ;$ e 9,3 nas eleições de 1990 a 2006, respectivamente (Carlos Melo, 2007). Apesar da estabilização do número de legendas em torno de trinta, a partir de 1994, e da concentração da votação em um número menor, estudos ainda indicam, com base na análise das mudanças de legenda durante a legislatura, a falta de coesão dos partidos (Mainwaring, 1999; Carlos Melo, 2004; 2006; 2007; Marenco dos Santos, 2001).

Outro aspecto do sistema, a descentralização ou a falta de uma coordenação nacional nos partidos, também tem sido reiterado. O fenômeno é antigo, tem sido objeto de diversas análises e é denominado de diferentes maneiras. Lima Júnior $(1983 ; 1993)$ verificou sua manifestação na existência de subsistemas partidários estaduais tanto no período de 1945 a 1964 quanto no atual; Nicolau (1996) aponta o federalismo dos partidos atuais. De maneira geral, o quadro é atribuído, como dito, à combinação de representação proporcional com lista aberta, federalismo, distritos de grande magnitude e monopólio, por parte de lideranças estaduais ou locais, da distribuição de recursos partidários (Abrucio, 1998; Ames, 2003; Mainwaring, 1999; Samuels, 2003). Shugart e Carey (1992) reforçam essas teses e apresentam mais uma sobre a dinâmica eleitoral brasileira: a natureza excessivamente representativa das

* Ver lista de siglas dos partidos políticos, com os respectivos significados, no final deste artigo. 
eleições presidenciais em detrimento da eficiência e, portanto, da accountability.

\section{A eficiência das eleições presidenciais e uma proposta de classificação dos partidos}

Como preveem Shugart e Carey (1992), a perspectiva de um segundo turno tem encorajado a apresentação de candidatos por um grande número de partidos nas cinco últimas eleições presidenciais. Esse número foi especialmente alto na primeira eleição, a de 1989, quando concorreram 21 candidatos (Tabela 1), mas caiu para uma média de 8,3 competidores nas quatro eleições subsequentes. Apesar dessa média ainda alta, a distribuição da votação entre os competidores concentra-se, na maioria das eleições a partir de 1994, em duas propostas de governo, que é o principal indicador de eficiência eleitoral.

Tabela 1

Competidores e Votação nas Eleições Presidenciais

(1989-2006)

\begin{tabular}{|c|c|c|c|c|c|c|}
\hline \multirow[t]{2}{*}{ Eleição } & \multicolumn{4}{|r|}{ Competidores } & \multicolumn{2}{|c|}{ Votação } \\
\hline & $\mathbf{N}$ & $\mathrm{Ne}$ & Partido & Coligação & $\%$ & $\%$ a. \\
\hline \multirow[t]{3}{*}{1989} & 21 & 5,7 & PRN & PRN-PST-PSL & 30,5 & 30,5 \\
\hline & & & PT & PT-PSB-PC do B & 17,2 & 47,7 \\
\hline & & & Outros & & 52,3 & 100 \\
\hline \multirow[t]{3}{*}{1994} & 8 & 2,7 & PSDB & PSDB-PFL-PTB & 54,3 & 54,3 \\
\hline & & & PT & PT-PSB-PC do B-PPS-PV-PSTU & 27,0 & 81,3 \\
\hline & & & Outros & & 18,7 & 100 \\
\hline \multirow[t]{3}{*}{1998} & 12 & 2,5 & PSDB & PSDB-PFL-PPB-PTB-PSD & 53,1 & 53,1 \\
\hline & & & PT & PT-PDT-PSB-PC do B & 31,7 & 84,8 \\
\hline & & & Outros & & 15,2 & 100 \\
\hline \multirow[t]{3}{*}{2002} & 6 & 3,2 & PT & PT-PCB-PL-PMN-PC do B & 46,4 & 46,4 \\
\hline & & & PSDB & PSDB-PMDB & 23,2 & 69,6 \\
\hline & & & Outros & & 30,4 & 100 \\
\hline \multirow[t]{3}{*}{2006} & 7 & 2,4 & PT & PT-PC do B-PRB & 48,6 & 48,6 \\
\hline & & & PSDB & PSDB-PFL & 41,6 & 90,2 \\
\hline & & & Outros & & 9,8 & 100 \\
\hline
\end{tabular}

Fontes: Tribunal Superior Eleitoral - TSE (2007); Melo (2006:164); banco de dados eleitorais do Brasil (1982 a 2006), organizado por Jairo Nicolau e disponível em http://jaironicolau.iuperj.br/ banco2004.html. Acessado em 2007. 
No primeiro turno da eleição de 1989, os candidatos mais votados, do PT e do PRN, reuniram 47,7\% da votação. Nessa ocasião, sobraram propostas de governo; partidos com longa trajetória, como o PMDB, tiveram votações inexpressivas; partidos destituídos de qualquer significado, como o PRN, lograram votações surpreendentes $(30,5 \%)$. Sobrou ineficiência, diriam Shugart e Carey, o que é indicado pelo alto número efetivo de partidos $(5,7)$.

Nas eleições de 1994, 1998, 2002 e 2006, a eficiência emerge. A disputa passa a ser coordenada pelos partidos, mais especificamente o PT e o PSDB, que se firmam "como alternativas de políticas perante o eleitorado nacional" (Melo, 2006:168), reunindo, nessas eleições, 81,3\%, $84,8 \%, 69,6 \%$ e $90,2 \%$ dos votos (média de $81,5 \%$ ). Com esses percentuais, o Brasil praticamente se equipara aos sistemas presidencialistas cujas eleições são classificadas como eficientes (média de 85\%)ํㅣㄹ 1994 e em 1998, não houve segundo turno e, em 2006, apesar de ter havido uma segunda rodada, os dois primeiros colocados obtiveram $90,2 \%$ dos votos na primeira. Nas eleições de 1994 a 2006, o número efetivo de partidos caiu para uma média de 2,72. Após a eleição de 1989, apenas duas vezes (1998 e 2002) o terceiro candidato obteve mais de $10 \%$ dos votos. Nos sistemas ineficientes, a votação dos terceiros candidatos reúne, em média, mais de 35\% da votação (Shugart e Carey, 1992). No Brasil, apenas em 1989 esse patamar foi ultrapassado. A média das quatro últimas eleições é de 18,5\%. Assim, o sistema, nas eleições executivas federais, não possui o formato multipartidário previsto. A distribuição dos votos entre os competidores, a partir de 1994, denota uma escolha entre uma proposta de governo ou outra, ou seja, eficiência.

Antes de avaliar o impacto da eficiência das eleições presidenciais sobre o desempenho eleitoral congressual dos partidos, cabe salientar que a simples participação na disputa presidencial é vista como um estímulo à convergência política, independentemente do grau de eficiência. As discussões de Duverger (1994) e Lima Júnior (1999) apontam nessa direção. Duverger discute o sistema partidário francês e distingue alguns fatores que propiciaram sua nacionalização. O primeiro é o uso do rádio e da televisão, que tornou a propaganda partidária mais uniforme no território e concentrada nas lideranças nacionais; o segundo, a capacidade dos partidos para reunir votos, o que, na visão do autor, depende de seu tamanho; o terceiro, a eleição popular do presidente da República. De acordo com Lima Júnior, a disputa presidencial 
brasileira, a partir da eleição de Jânio Quadros, tornou-se nacional tanto pelo tamanho e pela complexidade socioeconômica do eleitorado, além de pela magnitude do apoio necessário para a vitória presidencial, quanto pela necessidade de articulação política vertical e horizontal:

\begin{abstract}
Não se trata mais de um acerto político entre meia dúzia de oligarquias estaduais; não se trata mais de o detentor do poder escolher e fazer o seu sucessor; pelo contrário, a coalizão tem de ser bem mais ampla, incluindo grandes e pequenos estados. O apelo político tem de romper com particularidades locais e assumir um caráter mais geral, mais universal (ibidem:20).
\end{abstract}

Partindo dessas análises, pode-se argumentar, portanto, que a participação dos partidos na eleição presidencial estimula, nas elites partidárias, um esforço de articulação dos interesses de suas diversas bases eleitorais à proposta apresentada na campanha presidencial. Em um sistema com eleições presidenciais eficientes, esse esforço é estimulado, ademais, pela relação entre eficiência e desempenho eleitoral congressual, e pode-se esperar que ele se estenda à arena parlamentar, manifestando-se sob a forma de maior coordenação ou centralização das ações de liderança e das bancadas partidárias.

Apesar da eficiência, o grande número de competidores aconselha um olhar mais cuidadoso sobre a participação dos partidos nas eleições presidenciais brasileiras. A avaliação permitirá distinguir mais claramente aqueles que possuem estímulos à coordenação ou à centralização da ação parlamentar, por participarem com mais frequência e de forma mais consistente das eleições presidenciais, daqueles que não os possuem, seja porque participam dessas eleições apenas eventualmente, seja por apresentarem uma participação não consistente ao longo do tempo. Na Tabela 2, distingue-se a participação dos partidos nas cinco últimas eleições presidenciais em duas modalidades: apresentando candidato e participando de coligação.

Como pode ser visto, há significativa variação entre os partidos. Apresentando candidatos, PT e PSDB são os mais constantes competidores do atual período democrático. São seguidos pelo PDT e pelo $\mathrm{PCB} / \mathrm{PPS}^{3}$, que apresentaram candidatos em três eleições, e pelo PMDB e pelo PDS/PPR/PPB/PP4 (doravante PDS-PP), que disputaram apenas as duas primeiras eleições. PC do B, PSB, PFL e PTB têm se destacado como parceiros de coligações presidenciais. No entanto, en- 
Tabela 2

Modalidades de Participação dos Partidos nas Eleições Presidenciais (1989-2006)

\begin{tabular}{l|c|c|c}
\hline Partido & Apresentando Candidato & $\begin{array}{c}\text { Participando de } \\
\text { Coligação }\end{array}$ & $\begin{array}{c}\text { Total de } \\
\text { Participações }\end{array}$ \\
\hline PT & 5 & $-^{*}$ & 5 \\
PSDB & 5 & - & 5 \\
PDT & 3 & 2 & 5 \\
PC do B & - & 5 & 5 \\
PCB-PPS & 3 & 3 & 4 \\
PSB & 1 & 3 & 4 \\
PFL & 1 & 3 & 4 \\
PTB & 1 & 1 & 4 \\
PMDB & 2 & 1 & 3 \\
PDS-PP & 2 & 1 & 2 \\
PL & 1 & 1 & 3 \\
\hline
\end{tabular}

Fontes: TSE (2007); banco de dados eleitorais do Brasil (1982 a 2006), organizado por Jairo Nicolau e disponível em http:/ /jaironicolau.iuperj.br/banco2004.html. Acessado em 2007. Nota: * Dado numérico igual a zero.

quanto o PC do B e o PSB têm demonstrado apoio reiterado aos candidatos petistas, em cinco e três eleições, respectivamente, e o PFL, aos do PSDB, em três eleições, o PTB trocou, em 2002, o apoio aos candidatos do PSDB, das duas eleições anteriores, pelo apoio ao candidato do PCB-PPS. Não apresenta, portanto, um alinhamento consistente.

Supondo que a participação nas eleições presidenciais estimula maior grau de centralização política dos partidos, pode-se, a partir do número e da modalidade de participação, classificá-los. PMDB, PDS-PP, PLe PTB são competidores eventuais. Não atendem de forma contínua, ou consistente, no caso do PTB, ao critério proposto, o que permite esperar que suas lideranças sejam menos estimuladas a coerir em torno de uma proposta política mais abrangente na arena eleitoral e a coordenar seu comportamento parlamentar. Podem ser classificados, por isso, como partidos descentralizados. Por apresentarem candidatos reiteradamente ou um alinhamento partidário consistente, PT, PSDB, PDT, PCB-PPS, PSB, PC do B e PFL podem ser classificados como partidos centralizados. A variação em sua participação permite, no entanto, distinguir três subtipos de partidos centralizados: 1) PT e PSDB apresentam persistência na apresentação de candidatos e capacidade de angariar apoio eleitoral significativo, como visto na Tabela 1. São partidos de "vocação" presidencial. Nos termos propostos, são os partidos brasileiros com maior estímulo à centralização; 2) PDT e PCB-PPS apresentam candidatos recorrentemente, embora não com as mesmas fre- 
quência e capacidade de angariar votos que PT e PSDB. Possuem, portanto, uma vocação menos consistente, que pode ser denominada pretensão "presidencial"; 3) PC do B e PSB, por um lado, e PFL, por outro, são parceiros reiterados e leais, ou "coadjuvantes", de coligações lideradas, respectivamente, pelo PT e pelo PSDB. Apesar de não terem apresentado candidatos nas últimas eleições, com exceção do PSB, essa participação lhes exige permanentemente coordenação da ação política.

Constatada a eficiência das eleições presidenciais, resta a inconsistência do fenômeno em face dos incentivos institucionais, pelo menos nos termos de Shugart e Carey (1992). Embora as eleições executivas e legislativas tenham se tornado "casadas" em 1994, regra mais conducente à eficiência que a de "eleição solteira" que vigorou em 1989, como explicar eficiência em um sistema multipartidário com eleições em dois turnos? Duverger (1994), discutindo a polarização na Quinta República, sugere que ela foi propiciada pela combinação de votação em dois turnos, nas disputas presidenciais e legislativas, e pela força e disciplina adquiridas por um dos polos, o que lhe permitiria assumir e manter o poder. A votação em dois turnos não é, porém, indispensável para o surgimento de um sistema bipolar. Empiricamente, diz o autor, o bipolarismo surge

[...] quando acontece de um partido atrair quase a metade dos votos populares. Os outros são então forçados a se unir a fim de restabelecer um equilíbrio. Quando duas coalizões se confrontam, a representação proporcional dá a cada um de seus membros muita liberdade para consolidar um sistema bipolar do tipo francês (ibidem:84).

Assim, a polarização brasileira apresenta bastante similaridade com o caso francês: alianças partidárias consistentes na disputa presidencial e, como será visto, também nas congressuais, e a emergência de um partido que possui diversas semelhanças com os tradicionais partidos de massa europeus - o PT ${ }^{5}$. Esse partido se alia a outros de esquerda, especialmente o PC do B e o PSB, e lança uma ameaça bastante crível, já em 1989, de conquista do governo federal. Essa ameaça, concretizada em 2002, estimulou a aliança entre os partidos de centro e de direita, liderada pelo PSDB. O quadro é salientado por Carlos Melo (2007:280):

[...] a dinâmica presidencial vem gerando um efeito estruturante sobre o sistema partidário. À exceção da eleição de 1989, quando 21 partidos lançaram nomes à disputa, e o número efetivo de candidatos chegou a 
5,7 , nas quatro disputas seguintes o pleito foi polarizado por dois blocos, à frente dos quais se destacavam o PT e o PSDB. [...] os dois partidos [que] se firmaram como alternativas de polices perante o eleitorado nacional.

O "efeito estruturante" das eleições presidenciais sobre o sistema partidário brasileiro ocorre tanto no nível do eleitorado, o que é evidenciado pela vinculação da votação presidencial à congressual e pela maior volatilidade eleitoral dos partidos de vocação presidencial, quanto no nível das elites partidárias. Como dito, é justamente porque a eficiência das eleições presidenciais está associada ao comportamento do eleitor que ela vai influenciar as estratégias dos partidos que delas participam de forma reiterada e consistente, visando imprimir maior consistência, em termos nacionais, à legenda partidária.

\section{A influência da eficiência sobre o desempenho dos partidos nas eleições congressuais}

Em um sistema multipartidário, espera-se que a influência da eficiência das disputas presidenciais sobre as congressuais seja evidenciada pela vinculação entre os votos colocados nas urnas presidenciais e aqueles colocados nas congressuais. Um desempenho eleitoral congressual diferenciado dos competidores à Presidência é apontado por Fiorina (1974), Powell Jr. (2000) e Shugart e Carey (1992). Para Powell Jr., premiação e punição de governos, bem como a ordem das preferências manifestadas por propostas políticas ainda não testadas, abrem espaço para accountability e decisividade nos sistemas eficientes, o que seria indicado pela volatilidade mais alta dos votos dos partidos responsáveis pelo governo ${ }^{6}$.

No sistema brasileiro, argumentar sobre a influência das eleições presidenciais sobre as congressuais exige sempre contra-argumentar sobre o predomínio da influência do federalismo sobre o desempenho e o comportamento dos partidos. Considerando que a eficiência das eleições presidenciais é um fenômeno relativamente recente, cabe avaliar se ela produz alguma alteração nesse diagnóstico, pelo menos no que se refere ao desempenho eleitoral dos partidos e aos seus alinhamentos. A análise da influência sobre o desempenho eleitoral é feita a partir de dois indicadores: 1) volatilidade eleitoral nas eleições para a Câmara; 2) correlação entre a votação obtida pelos partidos nas eleições para as governadorias e para a Presidência e a que eles lograram nas elei- 
ções congressuais. Como a volatilidade eleitoral, a correlação permite verificar a influência da eficiência das disputas presidenciais sobre as congressuais, mas permite também comparar a influência exercida pelas duas eleições executivas (estadual e federal) sobre as congressuais ${ }^{7}$. A avaliação da influência da eleição presidencial sobre os alinhamentos partidários é feita pela análise das estratégias coligacionistas das elites nas disputas para a Câmara, o Senado e as governadorias.

As coligações são analisadas na próxima seção. A Tabela 3 traz a volatilidade por tipo de partido nas cinco últimas eleições para a Câmara.

Tabela 3

Volatilidade nas Eleições para a Câmara por Tipo de Partido

(1994-2006)

\begin{tabular}{|c|c|c|c|c|c|c|}
\hline \multirow{2}{*}{\multicolumn{2}{|c|}{ Tipo de Partido }} & \multicolumn{4}{|c|}{ Eleições } & \multirow{2}{*}{$\begin{array}{c}\text { Volatilidade } \\
\text { Média por Partido } \\
(1994-2006)\end{array}$} \\
\hline & & 1990-1994 & 1994-1998 & 1998-2002 & $2002-2006$ & \\
\hline \multirow[t]{3}{*}{ Centralizados } & Vocação & 4,1 & 1,8 & 4,2 & 2,1 & 1,5 \\
\hline & Coadjuvante & 0,5 & 3 & 3,4 & 1,8 & 0,7 \\
\hline & Pretensão & 1,7 & 1,1 & 1,2 & 0,6 & 0,6 \\
\hline \multicolumn{2}{|c|}{ Descentralizados } & 1,3 & 4,4 & 4,1 & 1,0 & 0,7 \\
\hline \multicolumn{2}{|l|}{ Micros } & 10,6 & 4,9 & 2,1 & 5,3 & 0,3 \\
\hline \multicolumn{2}{|c|}{$\begin{array}{l}\text { Volatilidade do sistema } \\
(\mathrm{N})\end{array}$} & $\begin{array}{l}18,1 \\
(37)\end{array}$ & $\begin{array}{l}15,1 \\
(32)\end{array}$ & $\begin{array}{c}15 \\
(31)\end{array}$ & $\begin{array}{l}10,8 \\
(33)\end{array}$ &..$^{*}$ \\
\hline
\end{tabular}

Fontes: TSE (2007); banco de dados eleitorais do Brasil (1982 a 2006), organizado por Jairo Nicolau e disponível em http:/ /jaironicolau.iuperj.br/banco2004.html. Acessado em 2007.

Nota: * Não se aplica dado numérico.

Os dados apresentados - mais especificamente o fato de a volatilidade média dos partidos de vocação presidencial ser mais que o dobro $(1,5)$ da que é apresentada pelos partidos de pretensão presidencial, pelos coadjuvantes e pelos descentralizados (em torno de 0,7 ) - mostram que o eleitor tem demonstrado capacidade de punir e de premiar, na eleição para a Câmara, os partidos responsáveis pelos governos anteriores e estabelecer ordem de preferência clara entre os competidores ainda não testados.

Uma análise mais detalhada dos dados eleitorais evidencia melhor o argumento. Em 1994, PT e PSDB reuniram 54,3\% e 27\% dos votos, respectivamente (conforme Tabela 1), no primeiro turno das eleições presidenciais. Na medida em que nenhum deles havia sido testado no go- 
verno, a votação reflete o ordenamento das preferências do eleitorado e a não punição ou a premiação pelo desempenho governamental. Esse mesmo ordenamento é replicado na votação desses partidos para a Câmara: PSDB cresce 5,3\% e PT, 2,9\% (a volatilidade de ambos é 4,1, conforme Tabela 3). Em 1998, não houve punição, mas sim premiação pelo desempenho do governo: o presidente da República é reeleito no primeiro turno, com 53,1\% dos votos, e o candidato do PT fica em segundo lugar na preferência do eleitorado (31,7\% dos votos). Esse ordenamento novamente se replica na votação para a Câmara: PSDB cresce 3,5\% e PT, 0,1\% (a volatilidade de ambos é 1,8). Nas eleições presidenciais de 2002, o eleitorado manifesta preferência pelo candidato do PT $(46,4 \%)$, embora não o suficiente para elegê-lo no primeiro turno, ficando o candidato do PSDB em segundo lugar, com 23,2\% dos votos. Embora esse resultado indique claramente preferência pelo PT, ele não nos permite afirmar que houve punição do PSDB pelo seu desempenho no governo. Na avaliação do desempenho eleitoral para a Câmara, no entanto, há indicação mais clara de punição e de preferência: PSDB perde 3,2\% dos votos conquistados em 1998; PT cresce sua votação em 5,2\% (a volatilidade de ambos fica em 4,2). Nas eleições presidenciais de 2006, os resultados eleitorais do primeiro turno são menos definitivos, refletindo a crise em que se debateu o governo Lula a partir de 2005: PT fica com 48,6\% da votação; PSDB, com 41,6\%. Na eleição para a Câmara, a punição ao PT é clara: perde 3,5\% dos votos conquistados em 2002. No entanto, esse resultado não favorece o PSDB, cuja votação cai 0,6\% (a volatilidade de ambos é 2,1).

Assim, é clara a influência da eficiência das eleições presidenciais sobre o desempenho eleitoral congressual dos partidos de vocação presidencial. No entanto, como mencionado, argumentar sobre a influência das eleições presidenciais sobre as congressuais exige sempre contra-argumentar sobre o predomínio da influência do federalismo sobre o desempenho e o comportamento dos partidos. Com o objetivo de comparar a influência das duas eleições executivas (federal e estadual) sobre o desempenho eleitoral para a Câmara e o Senado, apresento, na Tabela 4, a correlação entre as votações para esses cargos.

$\mathrm{Na}$ avaliação dos coeficientes, percebe-se, em primeiro lugar, que a correlação entre a votação para a escolha dos cargos executivos é maior com a votação para a Câmara que para o Senado. A explicação para a diferença encontra-se no sistema utilizado: o proporcional permite uma manifestação mais livre das preferências na medida em que dis- 
A Influência da Dinâmica Eleitoral sobre o Comportamento dos Partidos...

Tabela 4

Correlação entre a Votação dos Partidos nas Eleições para a Presidência e Governadorias e para a Câmara e o Senado (1990-2006) (Pearson)

\begin{tabular}{l|c|c|c|c}
\hline \multirow{2}{*}{ Eleição(1) $^{(1)}$} & \multicolumn{2}{|c|}{ Governadorias } & \multicolumn{2}{c}{ Presidência } \\
\cline { 2 - 5 } & Câmara & Senado & Câmara & Senado \\
\hline 1990 & 0,67 & $\ldots{ }^{(2)}$ & 0,24 & $\ldots$ \\
1994 & 0,59 & 0,45 & 0,21 & 0,26 \\
1998 & 0,74 & 0,46 & 0,83 & 0,46 \\
2002 & 0,59 & 0,38 & 0,72 & 0,57 \\
$2006^{(3)}$ & 0,68 & 0,24 & 0,72 & 0,34 \\
\hline
\end{tabular}

Fontes: TSE (2007); banco de dados eleitorais do Brasil (1982 a 2006), organizado por Jairo Nicolau e disponível em http:/ /jaironicolau.iuperj.br/banco2004.html. Acessado em 2007.

Notas: (1) Distribuição da votação por estado. (2) Dado numérico não disponível. (3) Nos dados do TSE, a votação para a Presidência, em 2006, inclui o exterior, além dos 27 estados; a votação para o Congresso, apenas os 27 estados. Para o cálculo, não incluí o exterior.

ponibiliza mais opções para o eleitor; o majoritário restringe a escolha ao limitar a oferta de candidatos (Sartori, 1994). Em segundo os coeficientes indicam correlação significativa entre o desempenho dos partidos que disputam as governadorias e seu desempenho nas eleições legislativas, especialmente para a Câmara, nas cinco últimas eleições. Em terceiro, a correlação entre o desempenho dos partidos que disputam a Presidência e seu desempenho para a Câmara foi muito baixa, é claro, em 1990, visto que a eleição presidencial ocorrera no ano anterior, e em 1994, quando as eleições já são concorrentes. No entanto, a partir de 1998, o quadro se inverte: a correlação entre a votação obtida pelos partidos que disputaram a Presidência e a que eles obtiveram nas disputas congressuais, especialmente para a Câmara, tornou-se mais alta. Assim, supondo que a correlação encontrada aumente a probabilidade de relações de influência, pode-se concluir que, apesar de as eleições para os governadores ainda influenciarem o desempenho congressual dos partidos, essa influência é menor, nas três últimas eleições, que a exercida pelas disputas presidenciais.

\section{A influência da eficiência sobre os alinhamentos partidários: as coligações eleitorais}

As coligações nas eleições proporcionais foram permitidas nas eleições de 1950 a 1962, proibidas pela Lei Orgânica dos Partidos Políticos, de 1971, e novamente liberadas a partir das eleições de 1986 (Lima Jú- 
nior, 1993). Entre 1986 e 1998, foi proibido aos partidos realizarem, para a Câmara, coligações diferentes das firmadas para as governadorias. Em 2002 e em 2006, o TSE exigiu a verticalização, ou seja, os partidos que participavam da disputa presidencial não puderam fazer coligações diferentes nas disputas para os outros cargos (federais e estaduais). Em 2006, foi aprovada a Emenda Constitucional no 52, que institui a não obrigatoriedade de se manter a mesma coligação nos diversos pleitos ${ }^{8}$.

Apesar de seu impacto positivo na proporcionalidade entre votos e cadeiras (Braga, 2006), essas coligações são uma das especificidades do sistema brasileiro mais condenadas na literatura. $\mathrm{O}$ argumento é que elas desvirtuam a representação, ao possibilitar a transferência de votos, e estimulam a fragmentação do sistema, ao permitir a sobrevivência de partidos que não lograriam ultrapassar o coeficiente eleitoral se concorressem isoladamente.

As primeiras teses sobre o comportamento coligacionista foram elaboradas por Soares (1964): a do esforço mínimo e a da resistência ideológica. A primeira supõe que os partidos, especialmente os pequenos, visam a ganhos eleitorais, e, por isso, o comportamento coligacionista denotaria racionalidade em face das instituições; a tese da resistência ideológica supõe a influência das ideologias dos partidos e de seu enraizamento social sobre o cálculo coligacionista. Lima Júnior e Lavareda introduzem argumentos novos no debate. Lima Júnior (1983) aponta a existência de "subsistemas partidários estaduais" regidos por diferentes racionalidades. A principal contribuição de Lavareda (1991) é mostrar que o cálculo coligacionista incorpora elementos estranhos à disputa proporcional federal. Constatando que os grandes partidos perdiam cadeiras para os pequenos, o autor argumenta que "[a]s coligações nesses pleitos [os proporcionais federais] funcionavam como instrumento de barganha para amealhar apoio de pequenos nas legendas nas eleições de soma zero - os pleitos majoritários de turno único para os executivos estaduais" (ibidem:115-116).

Entre os estudos que tratam das coligações do período atual, alguns comparam a influência exercida pelas eleições para a Presidência e governadorias sobre as coligações e votação congressuais. Nas coligações de 1994 e 1998 para a Câmara, Samuels (2003) conclui que há maior congruência com as que se fizeram para as governadorias que as firmadas para a Presidência. Na análise das votações e das coligações 
congressuais, de 1990 a 2002, Braga (2006a), por outro lado, conclui que, "dada a magnitude do colégio eleitoral da disputa presidencial, há, na verdade, um processo de articulação envolvendo as lideranças nacionais e estaduais para manter congruência nas coligações partidárias, de modo a aumentar as chances de êxito na eleição em nível nacional" (ibidem:281-282).

A análise das coligações aqui visa apenas verificar se a polarização que emerge na disputa presidencial se reflete no padrão aliancista dos partidos nas outras disputas. Para isso, avalio as estratégias de cada um dos onze maiores partidos (PC do B, PT, PSB, PDT, PCB-PPS, PSDB, PMDB, PL, PTB, PDS-PP, PFL), especificamente os parceiros de coligação por eles escolhidos. Entendo cada par de partidos, em uma coligação, como "aliança". Como a participação dos micropartidos dificulta a avaliação das estratégias dos maiores, procuro antes distinguir a contribuição desses dois grupos na evolução do número de coligações.

Tabela 5

Coligações por Tipo de Integrantes, Cargo e Eleição

(1990-2006)

\begin{tabular}{|c|c|c|c|c|c|}
\hline \multirow[t]{2}{*}{ Tipo de Coligações/Cargos } & \multicolumn{5}{|c|}{ Eleição } \\
\hline & 1990 & 1994 & 1998 & 2002 & 2006 \\
\hline \multicolumn{6}{|l|}{ Coligações (total) } \\
\hline Câmara & 85 & 113 & 104 & 139 & 144 \\
\hline Senado & $\ldots$ & 71 & 74 & 112 & 87 \\
\hline Governadorias & 82 & 78 & 83 & 106 & 105 \\
\hline \multicolumn{6}{|l|}{ Coligações apenas de micros } \\
\hline Câmara & 9 & 10 & 17 & 17 & 51 \\
\hline Senado & $\cdots$ & 4 & 8 & 7 & 20 \\
\hline Governadorias & 3 & 5 & 7 & 7 & 29 \\
\hline \multicolumn{6}{|c|}{ Coligações com pelo menos um dos maiores partidos } \\
\hline Câmara & 76 & 103 & 87 & 122 & 93 \\
\hline Senado & $\cdots$ & 67 & 66 & 105 & 68 \\
\hline Governadorias & 79 & 73 & 76 & 99 & 76 \\
\hline
\end{tabular}

Fontes: TSE (2007); banco de dados eleitorais do Brasil (1982 a 2006), organizado por Jairo Nicolau e disponível em http:/ /jaironicolau.iuperj.br/banco2004.html. Acessado em 2007.

A distribuição do número de "coligações (total)" (Tabela 5) mostra variação entre os cargos e, no mesmo cargo, entre as eleições. Para a Câmara, esse número apresenta crescimento em 1994, 2002 e 2006. Em 
1994, o aumento está relacionado com o comportamento dos partidos maiores, como pode ser visto pelo número de "coligações com pelo menos um dos maiores partidos". Em 2002, o aumento do total de coligações é explicado também pelo comportamento dos maiores partidos e está relacionado com a exigência de verticalização. Como mostra o aumento de "coligações com pelo menos um dos maiores partidos", naquelas eleições, esses partidos multiplicaram as coligações para os três cargos. Em 2006, o aumento no número de "coligações (total)" está relacionado com a participação eleitoral dos micros, como pode ser visto na evolução do número de "coligações apenas de micros".

O número de "coligações com pelo menos um dos maiores partidos" traz outras informações importantes. Em primeiro lugar, ele reflete o número de estados em que esses partidos participam de cada uma das disputas e suas preferências quanto às modalidades. Em segundo, percebe-se relativa estabilidade no número das coligações nas eleições para as governadorias (em torno de 76) e para o Senado (em torno de 66). Essa estabilidade é interrompida apenas em 2002 pela verticalização, como já salientado. Para a Câmara, não se pode falar em estabilidade: desconsiderando os aumentos de 1994 (de 76 para 103) e de 2002 (de 87 para 122), há um leve crescimento do número de coligações (em torno de 6) entre as outras eleições. Vejamos como esses partidos preferem competir nas eleições: se em alianças entre si ou em aliança apenas com micros ou isoladamente (Tabela 6).

Tabela 6

Modalidades de Participação dos Maiores Partidos por Cargo

(1990-2006)

\begin{tabular}{l|c|c|c|c|c}
\hline \multirow{2}{*}{ Modalidades } & \multicolumn{5}{c}{ Eleição } \\
\cline { 2 - 6 } & $\mathbf{1 9 9 0}$ & $\mathbf{1 9 9 4}$ & $\mathbf{1 9 9 8}$ & $\mathbf{2 0 0 2}$ & $\mathbf{2 0 0 6}$ \\
\hline Alianças entre dois dos maiores partidos \\
\hline Câmara & 240 & 329 & 362 & 202 & 314 \\
Senado & $\ldots$ & 197 & 350 & 200 & 344 \\
Governadorias & 390 & 283 & 449 & 202 & 379 \\
\hline Disputas isoladas de um dos maiores ou aliança apenas com micros & \\
\hline Câmara & 83 & 35 & 45 & 68 & 51 \\
Senado & $\ldots$ & 71 & 33 & 69 & 29 \\
Governadorias & 37 & 39 & 12 & 39 & 20 \\
\hline
\end{tabular}

Fontes: TSE (2007); banco de dados eleitorais do Brasil (1982 a 2006), organizado por Jairo Nicolau e disponível em http://jaironicolau.iuperj.br/banco2004.html. Acessado em 2007. 
Nas eleições para a Câmara, percebe-se um aumento significativo das alianças entre os maiores partidos em 1994 (329) e em 1998 (362), tendo-se por referência a eleição de 1990 (240 alianças). Em 2002, em virtude da verticalização, há uma queda brusca nessas alianças (202), mas, em 2006, elas voltam a crescer (314), ficando ainda em um patamar superior ao de 1990. Nas disputas para o Senado, esses partidos parecem aliar menos entre si nos anos em que dois terços das cadeiras estão em disputa, o que parece influenciar, inclusive, as estratégias adotadas nas eleições para as governadorias. A oscilação inversa do número de "disputas isoladas de um dos maiores ou aliança apenas com micros" parece confirmar essa tendência: nos anos em que dois terços das cadeiras estão em disputa, há aumento dessas modalidades de participação eleitoral.

O ponto a ser ressaltado é que, apesar de os maiores partidos terem aumentado, em relação à eleição de 1990, o número de alianças entre si nas eleições para a Câmara, especialmente em 1994 e em 1998, mostrando preferência pela acomodação diversificada do maior número possível de parceiros na coligação, a avaliação do número de alianças entre os partidos de vocação presidencial e seus coadjuvantes aponta claramente para a polarização antes mesmo da exigência de verticalização em 2002. Vejamos as alianças entre PT e PSDB (Tabela 7).

Os dois partidos de vocação presidencial participaram da mesma coligação nas eleições para a Câmara, em 1990, em três estados; em 1994 e em 1998, em dois. Para as governadorias, as escolhas são as mesmas, embora a participação tenha sido menor; para o Senado, o número de alianças entre eles é uma em 1994 e duas em 1998.

Os coadjuvantes seguem, em geral, estratégias semelhantes para a Câmara: o PC do B acompanha o PT na restrição das alianças com o PSDB; o PSB mantém o mesmo número em 1994 e em 1998. Cabe salientar que a polarização que existe entre o PT e o PFL é mais radical que a que se instalou entre o PT e o PSDB. Esses dois são os únicos partidos que nunca se aliaram nas disputas para o Legislativo federal, mostrando que a resistência ideológica no cálculo coligacionista, conforme Soares (1964), encontra evidências também no sistema atual, estando presente, até mesmo, na polarização pelo cargo presidencial. Nas eleições executivas estaduais, esses partidos também se colocaram sempre em campos opostos, exceto em 2002, quando integraram uma mesma coligação: a que lançou o candidato do PSL ao governo de Roraima. 
Tabela 7

Alianças entre Partidos de Vocação Presidencial por Cargo

(1990-2006)

\begin{tabular}{|c|c|c|c|c|c|c|c|}
\hline \multirow[t]{2}{*}{ Eleição } & \multirow[t]{2}{*}{ Partido } & \multicolumn{2}{|c|}{ Câmara } & \multicolumn{2}{|c|}{ Senado } & \multicolumn{2}{|c|}{ Governadorias } \\
\hline & & $\begin{array}{l}\text { Partici- } \\
\text { pações* }\end{array}$ & Alianças & $\begin{array}{l}\text { Partici- } \\
\text { pações }\end{array}$ & Alianças & $\begin{array}{l}\text { Partici- } \\
\text { pações }\end{array}$ & Alianças \\
\hline \multirow[t]{2}{*}{1990} & PT & 27 & \multirow[t]{2}{*}{3} & \multirow[t]{2}{*}{$\cdots$} & \multirow[t]{2}{*}{$\ldots$} & 21 & \multirow[t]{2}{*}{3} \\
\hline & PSDB & 27 & & & & 19 & \\
\hline \multirow[t]{2}{*}{1994} & PT & 27 & \multirow[t]{2}{*}{2} & 24 & \multirow[t]{2}{*}{1} & 25 & \multirow[t]{2}{*}{2} \\
\hline & PSDB & 27 & & 23 & & 21 & \\
\hline \multirow[t]{2}{*}{1998} & $\mathrm{PT}$ & 27 & \multirow[t]{2}{*}{2} & 26 & \multirow[t]{2}{*}{2} & 26 & \multirow[t]{2}{*}{2} \\
\hline & PSDB & 27 & & 23 & & 25 & \\
\hline \multirow[t]{2}{*}{2002} & PT & 27 & \multirow[t]{2}{*}{-} & 27 & \multirow[t]{2}{*}{-} & 25 & \multirow[t]{4}{*}{-} \\
\hline & PSDB & 27 & & 27 & & 23 & \\
\hline \multirow[t]{2}{*}{2006} & PT & 27 & \multirow[t]{2}{*}{-} & 25 & \multirow[t]{2}{*}{-} & 25 & \\
\hline & PSDB & 27 & & 24 & & 22 & \\
\hline
\end{tabular}

Fontes: TSE (2007); banco de dados eleitorais do Brasil (1982 a 2006), organizado por Jairo Nicolau e disponível em http:/ /jaironicolau.iuperj.br/banco2004.html. Acessado em 2007.

Nota: * Total de participações do PT e do PSDB, coligados ou isoladamente.

A consistência da polarização entre os partidos de vocação presidencial e seus coadjuvantes, nas eleições congressuais, pode ser avaliada, inclusive, em suas estratégias coligacionistas em 2006. Visando à acomodação diversificada do maior número de parceiros nos diversos pleitos, mas ainda sob a exigência de verticalização, todos os partidos restringiram ao máximo as coligações presidenciais. As únicas formalizadas foram justamente entre PT e PC do B, de um lado, e PSDB e PFL, de outro.

Assim, a análise da votação e das coligações dos partidos nas eleições presidenciais e congressuais mostra, em primeiro lugar, a eficiência das primeiras e sua influência sobre o desempenho dos partidos nas últimas, em detrimento, até mesmo, da influência das eleições para as governadorias; em segundo, que a polarização instalada na disputa presidencial permeou os cálculos das elites partidárias, quando da realização das coligações para o Congresso e até para as governadorias, mesmo antes que a lei o exigisse e simultaneamente ao aumento do número de alianças entre todos os maiores partidos. No que segue, é investigada a pertinência da classificação dos partidos em centraliza- 
dos e descentralizados para a previsão de seu comportamento parlamentar.

\section{A INFLUÊNCIA DA DINÂMICA ELEITORAL SOBRE 0 COMPORTAMENTO DOS PARTIDOS NA ARENA PARLAMENTAR}

Com o objetivo de avaliar se a dinâmica das eleições presidenciais e congressuais influencia o comportamento parlamentar dos partidos, testo três conjuntos de hipótese. Os dois primeiros focam o comportamento das lideranças; o último, o das bancadas partidárias. Os testes são realizados com dados das votações nominais da Câmara e do Senado.

\section{A Influência da Dinâmica Eleitoral sobre o Comportamento das Lideranças}

O comportamento das lideranças parlamentares pode ser avaliado a partir de duas variáveis: a coordenação que imprimem ao comportamento das bancadas partidárias nas votações e a coerência que mantêm entre o resultado das urnas e o posicionamento diante dos governos.

A coordenação do voto das bancadas parlamentares é uma estratégia potencialmente excelente para se adquirir visibilidade política. Para que um partido seja capaz de transmitir uma imagem com contornos minimamente definidos no sistema político brasileiro, em que o Executivo possui substantivo poder de agenda, faz-se necessário que aquele coloque sua marca na produção legislativa. Essa estratégia é feita de forma afirmativa, aprovando ou rejeitando as proposições, ou negativa, impedindo sua votação, o que pode ocorrer quando o líder declara obstrução, na tentativa de provocar falta de quórum. Por outro lado, sempre há votações em que parlamentares e lideranças preferem não se posicionar, mais especificamente as de projetos que contrariam os interesses de suas bases eleitorais. Nessas ocasiões, o encaminhamento é pela abstenção, o líder libera a bancada ou não encaminha a votação, ou seja, o partido não manifesta sua posição na votação e, assim, não se responsabiliza por seu resultado.

Dados esses nexos, é plausível esperar que: 1) os partidos centralizados utilizem mais a primeira estratégia - coordenem mais o comportamento das bancadas -, na medida em que estão, desde as eleições, responsabilizados pelas ações do governo ou contrários a elas, o que re- 
quer que imprimam visibilidade nacional à atuação partidária; 2) os partidos descentralizados utilizem mais a segunda estratégia - coordenem menos -, na medida em que, sendo sua constituency regional ou setorial, não possuem, em geral, interesse em aumentar a visibilidade nacional da legenda. Esses são os incentivos que advêm da arena eleitoral. Por outro lado, dadas as prerrogativas do Executivo no processo decisório, mais especificamente seu monopólio na distribuição de recursos importantes para os legisladores, é plausível esperar que, integrando a base governista e, portanto, tendo acesso aos recursos, as lideranças dos partidos descentralizados sejam mais estimuladas, negativa ou positivamente, a coordenar o comportamento de suas bancadas.

Para avaliar a coordenação, utilizo uma análise de regressão pelo método dos Mínimos Quadrados Ordinários (MQO). Os dados referem-se às votações realizadas na Câmara, distribuídas nas treze coalizões de governo do período de 1991 a 2007¹0. Os partidos analisados são: PT, PC do B, PSB, PDT, PCB-PPS, PSDB, PMDB, PL, PTB, PDS-PP, PFL.

As variáveis são: dependente: coordenação das lideranças parlamentares (\%), calculada da seguinte maneira: número de votações com encaminhamentos pela aprovação ou rejeição das proposições (sim, não) e pela obstrução da votação sobre o total de votações do período de vigência da coalizão; independentes: 1) eficiência eleitoral: dummy que distingue as coalizões do período com eleições eficientes daquelas do período com eleição não eficiente (categoria de referência: não eficiência para o período de 1991 a 1994); 2) tipo de partido: dummy que distingue partido centralizado de descentralizado ${ }^{11}$ (referência: descentralizado); 3) posição diante do governo: dummy que distingue a posição do partido diante do governo (referência: não integrado à base); 4) governo Lula: dummy que busca controlar diferenças na coordenação entre os governos no período com eleições eficientes (referência: governos Collor/Itamar e Fernando Henrique) ${ }^{12}$. No último modelo, substitui-se a variável eficiência por uma dummy para governos Fernando Henrique (referência: governos Collor/Itamar e Lula), a fim de verificar se há diferenças na coordenação apenas entre governos (Tabela 8).

As hipóteses estatísticas são: 1) no período com eleições eficientes, as lideranças coordenam mais o comportamento das bancadas que no período com eleição não eficiente; 2) as lideranças dos partidos centrali- 
A Influência da Dinâmica Eleitoral sobre o Comportamento dos Partidos...

Tabela 8

Regressão MQO - Coordenação Partidária na Câmara

$(1991-2007)^{(1)}$

\begin{tabular}{|c|c|c|c|c|}
\hline \multirow[t]{2}{*}{ Variáveis Independentes } & \multicolumn{4}{|c|}{ Coordenação das Lideranças Parlamentares $(\%)^{(2)}$} \\
\hline & 1 & 2 & 3 & 4 \\
\hline Constante & $\begin{array}{c}84,507^{* * *} \\
(1,762)\end{array}$ & $\begin{array}{c}84,870^{* * *} \\
(2,287)\end{array}$ & $\begin{array}{c}82,534^{* * *} \\
(2,568)\end{array}$ & $\begin{array}{c}82,534^{* * *} \\
(2,568)\end{array}$ \\
\hline Eficiência eleitoral & $\begin{array}{l}5,343^{* *} \\
(2,643)\end{array}$ & $\begin{array}{l}5,343^{* *} \\
(2,652)\end{array}$ & $\begin{array}{l}4,868^{* *} \\
(2,638)\end{array}$ & \\
\hline Governos Fernando Henrique & & & & $\begin{array}{l}4,868^{*} \\
(2,638)\end{array}$ \\
\hline Governo Lula & $\begin{array}{l}6,555^{* *} \\
(2,786)\end{array}$ & $\begin{array}{l}6,555^{* *} \\
(2,795)\end{array}$ & $\begin{array}{l}5,729 * * \\
(2,801)\end{array}$ & $\begin{array}{c}10,596^{* * *} \\
(2,711)\end{array}$ \\
\hline Tipo de partido & & $\begin{array}{c}-0,571 \\
(2,279)\end{array}$ & $\begin{array}{c}0,765 \\
(2,361)\end{array}$ & $\begin{array}{c}0,765 \\
(2,361)\end{array}$ \\
\hline Posição diante do governo & & & $\begin{array}{l}4,543^{*} \\
(2,352)\end{array}$ & $\begin{array}{l}4,543^{*} \\
(2,352)\end{array}$ \\
\hline $\mathrm{N}$ & $(143)$ & $(143)$ & $(143)$ & $(143)$ \\
\hline $\mathrm{R}^{2}$ & $12,6^{* * *}$ & $12,7^{* * *}$ & $15,0^{* * *}$ & $15,0^{* * *}$ \\
\hline $\mathrm{R}^{2}$ ajustado & 11,4 & 10,8 & 12,5 & 12,5 \\
\hline
\end{tabular}

Fonte: Banco de dados legislativos da Câmara dos Deputados (1989-2007), cedido por Figueiredo e Limongi.

Notas: $(1) * \mathrm{p}<0,10 ;{ }^{* *} \mathrm{p}<0,05 ;{ }^{* * *} \mathrm{p}<0,001$. Erro padrão entre parênteses. (2) Durbin-Watson $=$ 0,222 ; colinearidade entre todas as variáveis acima de 0,5 .

zados coordenam mais o comportamento das bancadas que as dos descentralizados; 3) as lideranças partidárias coordenam mais o comportamento das bancadas quando integram a coalizão governista que quando não integram.

No primeiro modelo, comprova-se a primeira hipótese. No período com eleições eficientes, as lideranças partidárias coordenam o comportamento das bancadas 5,343 pontos a mais que no período com eleição não eficiente ${ }^{13}$. No governo Lula, tendo-se por referência os governos anteriores, a coordenação é aumentada em 6,555 pontos. No segundo modelo, a introdução da variável tipo de partido altera muito pouco os resultados. Essa variável apresenta coeficiente baixo, sem significância estatística e no sentido contrário ao esperado $(-0,571)$. A capacidade explicativa de ambos os modelos é de $12,6 \%$ e de $12,7 \%$ da variação, respectivamente, com significância estatística em torno de $1 \%$. 
No terceiro modelo, em que se introduz a variável posição diante do governo, esses resultados são alterados: no período com eleições eficientes, os partidos coordenam o comportamento das bancadas 4,868 pontos a mais que no período com eleição não eficiente. $\mathrm{O}$ efeito cresce no governo Lula, quando a coordenação é de 5,729 pontos a mais que nos governos Collor/Itamar e Fernando Henrique. Ser partido centralizado, em relação a ser descentralizado, implica um aumento de 0,765 ponto na taxa de coordenação (sem significância estatística), efeito bem menor que aquele que se verifica quando o partido integra formalmente a base de apoio ao governo, que é de 4,543 pontos. Assim, a terceira hipótese encontra muito mais sustentação nos dados que a segunda: integrar a base governista motiva mais as lideranças a coordenarem a atuação das bancadas que ser centralizado. A capacidade explicativa do terceiro modelo é a mesma do quarto: 15\% da variação da taxa de coordenação, com significância estatística em torno de 1\%. No quarto modelo, a variável eficiência é substituída por governos Fernando Henrique, o que não altera os coeficientes das variáveis tipo de partido e posição diante do governo, mas contribui para especificar melhor a evolução da coordenação entre os governos: nos governos Fernando Henrique, a coordenação é 4,868 pontos a mais que nos governos Collor/Itamar; no governo Lula, 10,596 pontos a mais que nos anteriores.

De forma sucinta, os resultados mostram que: 1) não há diferença estatisticamente significativa entre a coordenação exercida pelos líderes dos partidos centralizados e descentralizados; 2) todos os partidos centralizados e descentralizados - coordenam muito mais o comportamento das bancadas quando integram a base do governo; 3) a coordenação nas votações nominais tem crescido significativamente ao longo do período. Assim, eles indicam, sobretudo, a crescente força dos incentivos (negativos ou positivos) fornecidos pelos governos aos partidos de sua base de apoio na Câmara dos Deputados.

Para o Senado, esse teste não pode ser realizado em virtude da não disponibilidade dos dados do período de 1991 a 1998; para o período de 1999 a 2007, pelo baixo número de encaminhamentos das lideranças dos partidos descentralizados ${ }^{14}$.

O segundo conjunto de hipóteses está relacionado com o grau de coerência que os partidos mantêm entre posicionamento eleitoral e posicionamento parlamentar. A expectativa é de que os partidos centrali- 
zados, por possuírem um horizonte político mais amplo, vinculem, de forma mais consistente que os descentralizados, o resultado das urnas a seu comportamento diante dos governos. As hipóteses específicas são testadas pela apresentação abaixo, em gráficos, da taxa de convergência entre os encaminhamentos do líder do governo e os dos líderes dos partidos centralizados, por subtipo, e descentralizados.

Primeira hipótese. Nas eleições eficientes, os partidos de vocação presidencial e seus coadjuvantes posicionam-se, na Câmara, de forma mais consistente na oposição ao governo quando perdem as eleições e o apoiam, também de forma mais consistente, quando o elegem (Gráfico 1).

A hipótese não é completamente comprovada no período com eleição não eficiente. Nas coalizões Collor 2 e Collor 3, apenas o PSDB se posiciona de forma ambígua; nas coalizões do governo Itamar, todos os partidos se posicionam de forma ambígua, com exceção do PSDB. No período com eleições eficientes, o resultado mostra-se conforme esperado: de 1995 a 2003, PT e seus coadjuvantes ficam na oposição ao governo eleito pelo PSDB e pelo PFL, exceto na última coalizão de Fernando Henrique II, quando o PT apresenta convergência com o líder do governo em 50\% das votações. De 2003 a 2007, esses competidores trocam de lugar: PT e seus coadjuvantes passam a apoiar o governo que elegeram; PSDB e PFL passam para a oposição clara. Apenas em

\section{Gráfico 1}

Convergência entre os Encaminhamentos do Líder do Governo e os Líderes dos Partidos de Vocação Presidencial e seus Coadjuvantes na Câmara (1991-2007)

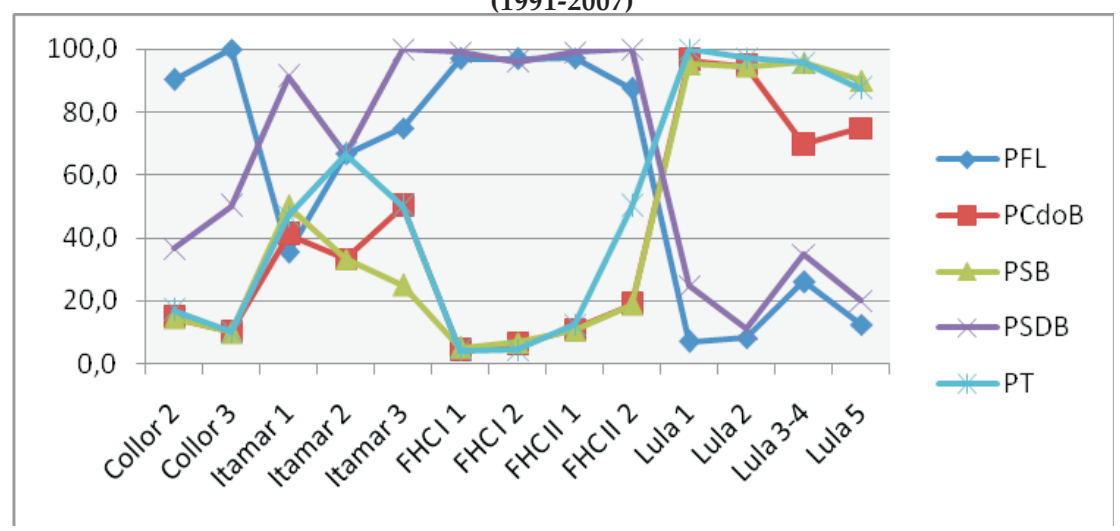

Fonte: Banco de dados legislativos da Câmara dos Deputados (1989-2007), cedido por Figueiredo e Limongi. 
2005, na coalizão Lula 3-4, esses dois partidos e o PC do B diminuem um pouco sua coerência, aumentando-a logo em seguida.

Segunda hipótese. No período com eleições eficientes, os partidos de pretensão presidencial são mais coerentes com seu posicionamento eleitoral que no período com eleição não eficiente (Gráfico 2).

Dado que PDT e PPS não elegeram seus candidatos presidenciais, seu comportamento em relação ao governo, nos dois períodos (eficiente e não eficiente), deve ser analisado considerando-se seu alinhamento nas eleições. A hipótese de menor coerência no período, com eleição não eficiente, não encontra sustentação nos dados: os dois partidos fizeram oposição consistente ao governo a que se opuseram na arena eleitoral. Essa mesma coerência é constatada no período com eleições eficientes, conforme esperado: sendo partidos de esquerda e não se tendo alinhado ao PSDB em 1994 e em 1998, ambos se posicionam claramente na oposição (convergência menor que 40\%). Essa estratégia mostra capacidade de sobrevivência política independentemente dos recursos que podem ser auferidos quando se integra a base governista e, assim, esforço em manter a consistência eleitoral da legenda. A mesma coerência é apresentada no governo de centro-esquerda de Lula. Embora tenham inicialmente integrado sua base de sustentação, apoiando-o consistentemente nas duas primeiras coalizões, ambos diminuem bastante o apoio, a partir de 2004, e se desligam do governo, no

\section{Gráfico 2}

Convergência entre os Encaminhamentos do Líder do Governo e os Líderes dos Partidos de Pretensão Presidencial na Câmara dos Deputados

(1991-2007)

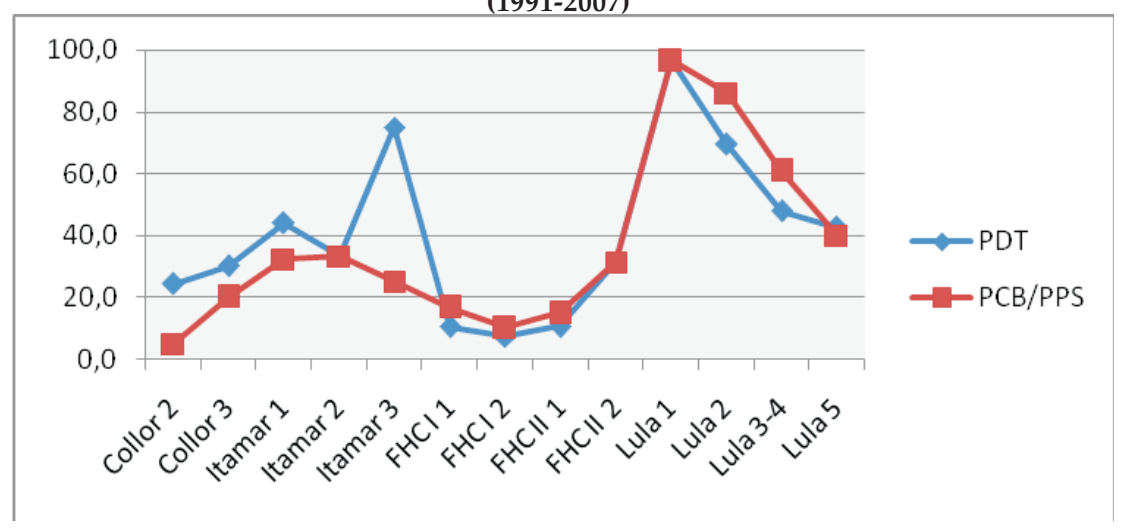

Fonte: Banco de dados legislativos da Câmara dos Deputados (1989-2007), cedido por Figueiredo e Limongi. 
início de 2005, quando entendem que o alinhamento poderia prejudicar o valor eleitoral da legenda.

Terceira hipótese. Os partidos descentralizados apresentam, na Câmara, comportamento menos autônomo em relação ao governo que os centralizados, independentemente da natureza das eleições e de seu alinhamento eleitoral (Gráfico 3).

Conforme esperado, diferentemente dos partidos centralizados, a tendência entre os descentralizados é de alinhamento ao governo, independentemente de integrarem formalmente sua base de apoio, da ideologia e da natureza das eleições. Apenas o PDS-PP, até Fernando Henrique I, e o PL, na segunda coalizão de Fernando Henrique I e na primeira de Fernando Henrique II, marcaram posição mais clara na oposição (convergência menor que $40 \%$ ). Todos os outros partidos, em todas as outras coalizões, apresentam taxas de convergência maiores que $50 \%$.

O teste dessas hipóteses também fica prejudicado no Senado Federal. No Gráfico 4, em caráter apenas ilustrativo, apresento as taxas de convergência entre os encaminhamentos dos líderes dos governos e os dos partidos que encaminharam frequentemente a votação nas coalizões de Fernando Henrique II e Lula.

\section{Gráfico 3}

Convergência entre os Encaminhamentos do Líder do Governo e os Líderes dos Partidos Descentralizados na Câmara dos Deputados

(1991-2007)

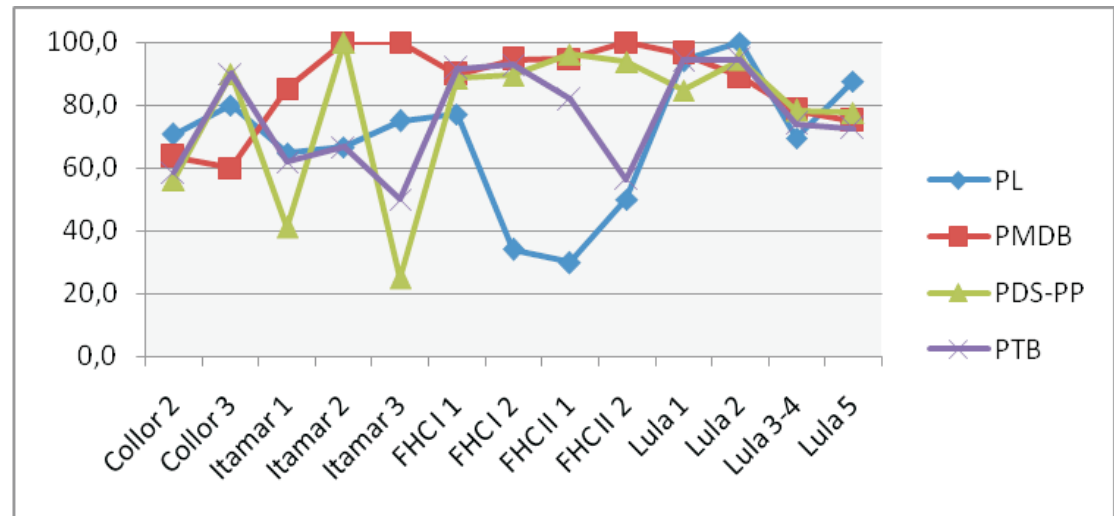

Fonte: Banco de dados legislativos da Câmara dos Deputados (1989-2007), cedido por Figueiredo e Limongi. 
Gráfico 4

Convergência entre os Encaminhamentos do Líder do Governo e os Líderes do PFL, do PSDB, do PT e do PMDB no Senado Federal

(1995-2007)

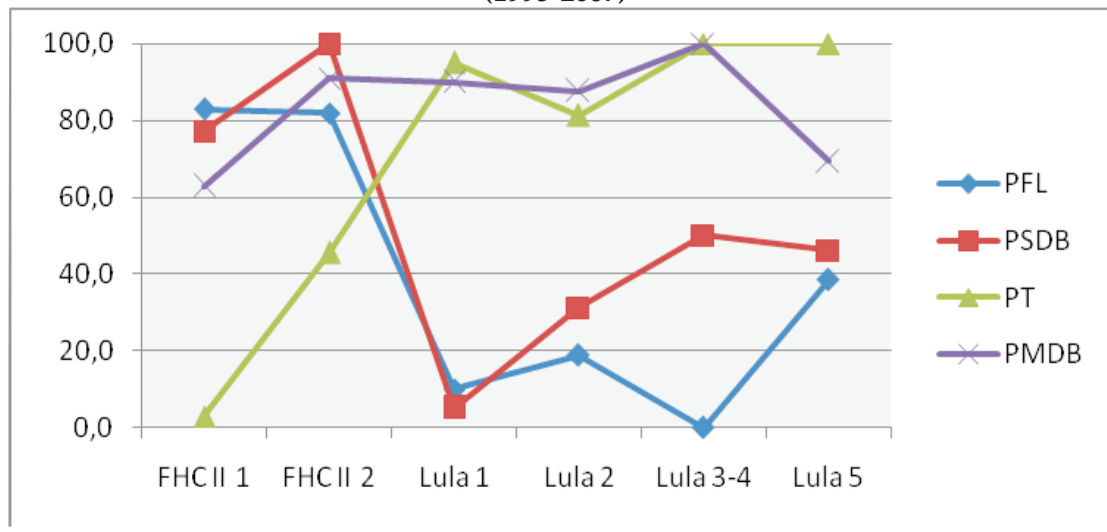

Fontes: Banco de dados legislativos do Senado Federal (1989-2007), cedido por Figueiredo e Limongi; diários e listas de votações nominais do Senado Federal.

Como pode ser visto, no Senado Federal, PSDB, PT, PFL e PMDB apresentam padrões de comportamento bastante semelhantes aos verificados na Câmara dos Deputados. PFL e PSDB transformam o apoio convicto oferecido ao governo Fernando Henrique em oposição ostensiva ao governo Lula, sendo que o último, no entanto, diminui a oposição em 2005; PT passa da oposição ao segundo governo Fernando Henrique, no qual a convergência máxima com o governo foi em $45 \%$ das votações da segunda coalizão, para o apoio sem reservas ao governo Lula; PMDB aparece sempre apoiando os governos, independentemente de estar formalmente integrado à base governista e de seu alinhamento nas eleições.

Assim, o tipo de participação dos partidos nas eleições presidenciais e o resultado das urnas se mostram como critérios pertinentes para a previsão do comportamento de seus líderes, em relação ao governo, na arena parlamentar. Embora a diferença entre os períodos não seja a esperada, os dados indicam que os partidos que participam reiteradamente das eleições presidenciais - os centralizados - mantêm significativa consistência em seu posicionamento ideológico e maior coerência, quando comparados aos descentralizados, entre o resultado das urnas e seu posicionamento diante do governo. Esse comportamento mostra maior independência em relação aos recursos que podem ser auferidos quando se integra a base governista, indicando que o inte- 
resse em manter a consistência nacional da legenda partidária orienta predominantemente suas estratégias.

\section{A Influência da Dinâmica Eleitoral sobre o Comportamento das Bancadas}

Na avaliação do comportamento das bancadas nas votações nominais, espera-se que os incentivos derivados da dinâmica eleitoral influenciem sua disposição ${ }^{15}$ em face dos recursos fornecidos pelo Poder Executivo e pelas lideranças parlamentares, que personificam os interesses do partido na Câmara e no Senado e, consequentemente, sua disciplina.

Para o teste, utilizo também a regressão MQO. A variável dependente é indice de fidelidade partidária ${ }^{16}$. Os partidos analisados são: PT, PC do B, PSB, PDT, PPS, PSDB, PMDB, PL, PTB, PDS-PP e PFL. Os dados das votações nominais da Câmara estão distribuídos em treze coalizões de governo do período de 1991 a $2007^{17}$. As hipóteses estatísticas são: 1) nas coalizões do período com eleições eficientes, os partidos são mais disciplinados que nas do período não eficiente; 2) os partidos centralizados são mais disciplinados que os descentralizados; 3) os partidos centralizados são mais disciplinados que os descentralizados quando integram a base governista que quando não integram.

Argumentei que os partidos centralizados são aqueles que, por sua participação reiterada e consistente nas disputas presidenciais, se esforçam por coordenar, na arena congressual, os interesses de suas bases eleitorais em torno da proposta que apresentam ou apoiam na disputa presidencial, e que esse comportamento denota centralização em torno de políticas e visa à maximização do valor eleitoral da legenda partidária. O suposto é que esses partidos sejam, portanto, politicamente mais coesos e que essa coesão seja revelada, até mesmo, por uma maior disciplina parlamentar.

Com o objetivo de verificar se essa coesão política não é influenciada por uma variável que antecede a própria inserção dos partidos na arena eleitoral, qual seja, uma coesão fundamentada em incentivos de identidade, estimulada pelo tipo de organização partidária, nos termos sugeridos por Panebianco (1990) e Sartori (1994), utilizo o percentual de membros do partido com tempo de filiação superior a oito anos como indicador de coesão organizacional. O procedimento parece pertinente, pois a coesão organizacional resulta do compartilhamento de 
valores, da adesão dos membros ao programa ou a causas do partido que, supostamente, varia com o tempo de convivência ${ }^{18}$. A partir disso, acrescento mais duas hipóteses às enunciadas anteriormente: 4) quanto maior o percentual de membros com tempo de filiação superior a oito anos no partido, maior a disciplina; 5) o efeito da coesão política sobre a disciplina é independente do efeito da coesão organizacional.

As variáveis independentes são: 1) eficiência eleitoral: dummy que distingue as coalizões do período com eleições eficientes das do período com eleição não eficiente (categoria de referência: não eficiência); 2) tipo de partido: dummy que distingue partido centralizado de partido descentralizado (referência: descentralizado); 3) posição diante do governo: dummy que distingue a posição do partido diante do governo (referência: não integrado à base governista); 4) tipo*posição: variável que objetiva captar o efeito de interação entre ser centralizado e estar formalmente integrado à base governista; 5) governo Lula: dummy que tem por objetivo distinguir diferenças entre os governos (referência: governos Fernando Henrique e governos Collor e Itamar). O controle das diferenças entre os governos Itamar e Collor, por um lado, e os governos de Fernando Henrique e de Lula, por outro, ocorre pela variável eficiência. Buscando controlar variações apenas entre os governos, testo, por fim, a substituição da variável eficiência por uma dummy para os governos Fernando Henrique; 6) Membros com filiação = oito anos: percentual de membros com tempo de filiação igual ou maior a oito anos (Tabela 9).

A hipótese de que os partidos são mais disciplinados no período com eleições eficientes que no período anterior é refutada no primeiro modelo. O efeito agregado das variáveis eficiência eleitoral e governo Lula explica menos de $2 \%$ da variação do índice de fidelidade entre os partidos, sem significância estatística. A refutação dessa hipótese mostra que aquilo que pode ser corriqueiro e até banal nos sistemas eficientes parlamentaristas ou presidencialistas com reduzido número de partidos não é válido para o sistema brasileiro, independentemente de outras especificações.

No segundo modelo, em que se introduz a primeira e principal especificação, a variável tipo de partido, logra-se explicar $20 \%$ da variação no índice de fidelidade, com significância estatística em torno de 1\%. Ser partido centralizado, tendo-se por referência ser descentralizado, implica um aumento no índice de 5,853 pontos. Corrobora-se, portanto, a 
A Influência da Dinâmica Eleitoral sobre o Comportamento dos Partidos...

Tabela 9

Regressão MQO - Índice de Fidelidade Partidária na Câmara

$(1991-2007)^{(1)}$

\begin{tabular}{|c|c|c|c|c|c|c|}
\hline \multirow{2}{*}{$\begin{array}{l}\text { Variáveis } \\
\text { Independentes }\end{array}$} & \multicolumn{6}{|c|}{ Índice de Fidelidade Partidária ${ }^{(2)}$} \\
\hline & 1 & 2 & 3 & 4 & 5 & 6 \\
\hline Constante & $\begin{array}{c}90,549^{* * *} \\
(0,882)\end{array}$ & $\begin{array}{c}86,824^{* * *} \\
(1,031)\end{array}$ & $\begin{array}{c}86,541^{* * *} \\
(1,172)\end{array}$ & $\begin{array}{c}88,523^{* * *} \\
(1,334)\end{array}$ & $\begin{array}{c}86,862^{* * *} \\
(1,460)\end{array}$ & $\begin{array}{c}86,862^{* * *} \\
(1,460)\end{array}$ \\
\hline Eficiência eleitoral & $\begin{array}{l}-0,490 \\
(1,323)\end{array}$ & $\begin{array}{l}-0,490 \\
(1,196)\end{array}$ & $\begin{array}{l}-0,548 \\
(1,204)\end{array}$ & $\begin{array}{l}-1,197 \\
(1,195)\end{array}$ & $\begin{array}{l}-1,714 \\
(1,189)\end{array}$ & \\
\hline $\begin{array}{l}\text { Governos Fernando } \\
\text { Henrique }\end{array}$ & & & & & & $\begin{array}{l}-1,714 \\
(1,189)\end{array}$ \\
\hline Governo Lula & $\begin{array}{l}-1,468 \\
(1,395)\end{array}$ & $\begin{array}{l}-1,468 \\
(1,260)\end{array}$ & $\begin{array}{l}-1,568 \\
(1,279)\end{array}$ & $\begin{array}{l}-2,173^{*} \\
(1,264)\end{array}$ & $\begin{array}{l}-2,153^{*} \\
(1,239)\end{array}$ & $\begin{array}{c}-3,867^{* * *} \\
(1,272)\end{array}$ \\
\hline Tipo de partido & & $\begin{array}{c}5,853^{* * *} \\
(1,028)\end{array}$ & $\begin{array}{l}6,015^{* * *} \\
(1,077)\end{array}$ & $\begin{array}{c}4,032^{* * *} \\
(1,257)\end{array}$ & $\begin{array}{c}3,847^{* * *} \\
(1,234)\end{array}$ & $\begin{array}{c}3,847^{* * *} \\
(1,234)\end{array}$ \\
\hline $\begin{array}{l}\text { Posição diante do } \\
\text { governo }\end{array}$ & & & $\begin{array}{c}0,550 \\
(1,074)\end{array}$ & $\begin{array}{l}-1,648 \\
(1,296)\end{array}$ & $\begin{array}{l}-0,880 \\
(1,306)\end{array}$ & $\begin{array}{l}-0,880 \\
(1,306)\end{array}$ \\
\hline Tipo*posição & & & & $\begin{array}{c}5,527^{* * *} \\
(1,924)\end{array}$ & $\begin{array}{l}4,737^{* *} \\
(1,911)\end{array}$ & $\begin{array}{l}4,737^{* *} \\
(1,911)\end{array}$ \\
\hline $\begin{array}{l}\text { Membros com } \geq \text { oito } \\
\text { anos de filiação (\%) }\end{array}$ & & & & & $\begin{array}{l}0,042^{* *} \\
(0,017)\end{array}$ & $\begin{array}{l}0,042^{* *} \\
(0,017)\end{array}$ \\
\hline $\mathrm{N}$ & $(143)$ & $(143)$ & $(143)$ & $(143)$ & $(143)$ & $(143)$ \\
\hline $\mathrm{R}^{2}$ & 1,6 & $20,2^{* * *}$ & $20,4^{* * *}$ & $24,9 * * *$ & $28,4^{* * *}$ & $28,4^{* * *}$ \\
\hline $\mathrm{R}^{2}$ ajustado & 0,2 & 18,5 & 18,1 & 22,2 & 25,2 & 25,2 \\
\hline
\end{tabular}

Fonte: Banco de dados legislativos da Câmara dos Deputados (1989-2007), cedido por Figueiredo e Limongi.

Notas: $(1) * \mathrm{p}<0,10 ;{ }^{* *} \mathrm{p}<0,05 ;{ }^{* *} \mathrm{p}<0,001$. Erro padrão entre parênteses. (2) Durbin-Watson $=$ 1,767; a colinearidade fica no nível tolerado (acima de 0,5$)$, exceto a variável de interação $(0,47)$.

segunda hipótese. Os coeficientes das variáveis eficiência e governo Lula permanecem com sinal contrário ao esperado e sem significância estatística: no período com eleições eficientes, os partidos apresentam menor disciplina (-0,490 pontos) que no período não eficiente e, no governo Lula, diminuem ainda mais o índice $(-1,468)$.

No terceiro modelo, em que se introduz a variável posição diante do governo, o efeito da variável tipo de partido cresce: ser centralizado implica um aumento de 6,015 pontos no índice de fidelidade, e estar formalmente integrado à base do governo implica um aumento de 0,550 pon- 
to (sem significância estatística). As variáveis eficiência e governo Lula também têm seu efeito aumentado, continuando com o sinal inverso ao esperado e sem significância estatística: os partidos no período com eleições eficientes e, dentro desse período, no governo Lula, têm seu índice diminuído em 0,548 e 1,568 ponto, respectivamente. Esse modelo apresenta praticamente a mesma capacidade explicativa do anterior (20\%) e é estatisticamente significativo também em torno de $1 \%$.

No quarto modelo, em que é inserida a variável tipo* posição, logra-se explicar em torno de $25 \%$ da variação. No período com eleições eficientes, os partidos são menos disciplinados em 1,197 ponto (sem significância estatística) em relação ao período com eleição não eficiente. A queda no índice aumenta para 1,648 ponto (também sem significância estatística), quando os partidos estão formalmente integrados à base, e para 2,173 pontos no governo Lula, tendo-se por referência os governos Collor/Itamar e Fernando Henrique. O efeito da variável tipo de partido permanece positivo e de considerável magnitude: os partidos centralizados são mais disciplinados que os descentralizados em 4,032 pontos. O coeficiente da variável tipo* posição mostra que esses partidos aumentam sua disciplina especialmente quando estão formalmente integrados à base do governo: o índice aumenta 5,527 pontos.

No modelo 5, em que se inclui a variável relacionada ao tempo de filiação, explica-se 28,4\% da variação (nível de significância de 1\%). Em relação ao modelo anterior, há alterações na magnitude dos coeficientes: no período com eleições eficientes, os partidos são menos disciplinados em 1,714 ponto e, quando integram formalmente a base governista, sua disciplina diminui em 0,880 ponto (ambos os coeficientes sem significância estatística); a queda é especialmente grande no governo Lula, quando o índice diminui em 2,153 pontos. Os coeficientes das variáveis tipo de partido e tipo* posição permanecem altos e positivos: ser centralizado implica um aumento no índice de 3,847; ser centralizado e integrar formalmente a base governista, um aumento de 4,737 pontos. Por fim, o coeficiente da variável que mede o efeito do percentual de membros do partido com tempo de filiação igual ou superior a oito anos indica um efeito também considerável: a cada $10 \%$ de aumento no tamanho desse grupo dentro do partido, seu índice fica acrescido em 0,420 ponto. Isso significa que um partido, em que todos os membros possuem oito ou mais anos de filiação, terá seu índice acrescido em 4,200 pontos. Comprova-se, assim, a quarta hipótese: a coesão organizacional influencia positivamente a disciplina parlamentar. A manu- 
tenção da significância estatística e da considerável magnitude dos coeficientes das variáveis tipo de partido e tipo*posição, nesse modelo, corrobora também a quinta hipótese: a coesão política influencia a disciplina partidária independentemente da coesão organizacional.

No modelo 6, a variável eficiência é substituída por governos Fernando Henrique. O procedimento não altera a magnitude e a significância estatística dos coeficientes das outras variáveis, mas especifica melhor a evolução da disciplina no período. Os partidos nos governos Fernando Henrique, tendo-se por referência os anteriores, têm seu índice diminuído em 1,714 pontos (ainda sem significância estatística); no governo Lula, a queda é de 3,867 pontos. Esse modelo possui significância estatística em torno de $1 \%$ e sua capacidade para explicar a variação do índice de fidelidade partidária é de $28,4 \%$.

Para o Senado, os dados disponíveis referem-se ao período de 1999 a 2007, o que impossibilita o teste da hipótese relacionada à eficiência. Infelizmente, os dados sobre o tempo de filiação dos senadores também não estão disponíveis. Na Tabela 10, apresento os coeficientes en-

Tabela 10

Regressão MQO - Índice de Fidelidade Partidária no Senado

$(1999-2007)^{(1)}$

\begin{tabular}{l|c|c|c}
\hline \multirow{2}{*}{ Variáveis Independentes } & \multicolumn{3}{|c}{ Índice de Fidelidade Partidária } \\
\cline { 2 - 4 } & $\mathbf{( 1 )}$ & $\mathbf{( 2 )}$ & $\mathbf{( 3 )}$ \\
\hline Constante & $89,994^{* * *}$ & $90,063^{* * *}$ & $86,391^{* * *}$ \\
& $(1,818)$ & $(2,386)$ & $(2,970)$ \\
Governo Lula & $-1,358$ & $-1,361$ & $-2,381$ \\
& $(2,260)$ & $(1,284)$ & $(2,278)$ \\
Tipo de partido & & $-0,103$ & 2,141 \\
& & $(2,284)$ & $(2,492)$ \\
Posição diante do governo & & & $4,896^{*}$ \\
& & & $(2,477)$ \\
\hline N & 51 & 51 & 51 \\
$\mathrm{R}^{2}$ & 0,7 & 0,7 & 8,4 \\
$\mathrm{R}^{2}$ ajustado & $-1,3$ & 3,4 & 2,5 \\
\hline
\end{tabular}

Fontes: Banco de dados legislativos do Senado Federal (1989-2007), cedido por Figueiredo e Limongi; diários e listas de votações nominais do Senado Federal.

Notas: $(1)^{*} \mathrm{p}<0,10 ;{ }^{* *} \mathrm{p}<0,05 ;{ }^{* * *} \mathrm{p}<0,001$. Erro padrão entre parênteses; (2) Durbin-Watson = 1,562 , colinearidade acima de 0,5 . A inclusão de variável tipo ${ }^{*}$ posição prejudicou a colinearidade e foi retirada. 
contrados no teste de duas hipóteses: 1) os partidos centralizados são mais disciplinados que os descentralizados; 2) os partidos são mais disciplinados quando integram a base governista que quando não integram.

No Senado, os resultados encontrados indicam baixo efeito das variáveis selecionadas sobre a variação do índice. O último modelo explica apenas $8,4 \%$ da variação e não é estatisticamente significativo. De qualquer forma, é possível verificar que os partidos formalmente integrados à base são 4,896 pontos mais disciplinados que os não integrados e que ser centralizado implica um aumento no índice de 2,141 pontos (sem significância estatística). Os partidos no Senado são também menos disciplinados no governo Lula que no governo anterior: a diferença é de 2,381 pontos, também sem significância estatística.

\section{CONCLUSÃO}

O objetivo da discussão desenvolvida neste artigo foi explicar, a partir de fatores relacionados à dinâmica da arena eleitoral, a variação no comportamento dos partidos na arena parlamentar. Pela análise da votação e das coligações realizadas nas eleições presidenciais e congressuais, verificou-se que as primeiras tornaram-se eficientes, a partir de 1994, e passaram a influenciar o desempenho e as estratégias coligacionistas dos partidos nas disputas congressuais, especificamente daqueles que apresentaram candidatos presidenciais de forma reiterada ou apoiaram candidatos de outros partidos de forma consistente.

Com base nesses achados, argumentei que o tipo de posicionamento dos partidos nas eleições presidenciais influencia seu comportamento parlamentar: os participantes reiterados e consistentes - denominados centralizados - comportam-se de forma mais coordenada, a fim de manter ou aumentar a consistência nacional da legenda partidária, dada a influência da eficiência sobre seu desempenho eleitoral congressual, e como resultado da coesão política, estimulada pela própria participação nas disputas presidenciais; esse interesse e o esforço de coordenação da ação parlamentar não foram esperados dos participantes eventuais, denominados, por isso, descentralizados. As evidências de que o posicionamento dos partidos nas eleições presidenciais influencia sua atuação parlamentar foram buscadas no comportamento das lideranças e das bancadas partidárias nas votações nominais. 
Os testes que trataram do comportamento dos líderes, na Câmara, mostraram que: 1) eles coordenam mais o comportamento das bancadas no período com eleições eficientes que o fizeram no período anterior, especialmente quando integram a base governista; 2) as lideranças dos partidos centralizados, no período com eleições eficientes, mantêm maior coerência que as dos centralizados entre o resultado das eleições ou sua posição ideológica e seu posicionamento diante do governo, responsabilizando-se por seus projetos ou opondo-se a eles mais consistentemente. Desses achados, pode-se concluir, em primeiro lugar, que o crescente esforço de coordenação por parte das lideranças (dos partidos centralizados e descentralizados) foi estimulado pela polarização que se instalou no sistema, o que é claramente resultado da eficiência, mas é preciso salientar que os estímulos variam de acordo com a posição política. Para os partidos que fazem oposição ao governo, que são normalmente, como visto, apenas os centralizados, esse esforço está relacionado com o interesse em imprimir visibilidade à atuação do partido, marcando assim posição junto ao eleitorado. Para os partidos da base governista, por outro lado, o esforço de coordenação pode ser atribuído também aos incentivos seletivos (negativos e positivos) que eles recebem do governo; por exemplo, a possibilidade de execução de emendas orçamentárias e de acesso a recursos extraorçamentários ou a cargos públicos. Como os dois tipos de partido coordenam mais o comportamento das bancadas quando integram a base governista, pode-se inferir que, no caso dos partidos centralizados, esses incentivos se acumulam com os estímulos que advêm da arena eleitoral; no caso dos descentralizados, os incentivos do governo são, da perspectiva aqui adotada, os principais.

$\mathrm{Na}$ investigação do comportamento das bancadas, foi evidenciado que: 1) integrar a base governista influencia a disciplina parlamentar de forma negativa, embora estatisticamente não significativa. No entanto, controlada a disciplina pelo tipo de partido, verifica-se, de forma estatisticamente significativa, que 2) as bancadas dos partidos centralizados são mais disciplinadas que as dos descentralizados e, quando integram a base governista, sua disciplina aumenta ainda mais;3) a coesão que se forja no âmbito organizacional influencia positivamente a disciplina, mas de forma independente da coesão política, construída na dinâmica das eleições; 4 ) os partidos diminuíram sua disciplina ao longo dos governos analisados.

A queda na disciplina partidária ao longo do período, que contrariou a expectativa de que a eficiência eleitoral a influenciasse positivamente, 
e o fato de a participação na base governista também não influenciá-la significativamente, e muito menos de forma positiva, devem ser analisados em conjunto com o aumento da coordenação exercida pelas lideranças ao longo do período. Ao coordenarem mais o comportamento das bancadas, os líderes passaram a exigir dos parlamentares um posicionamento explícito em votações conflituosas, inclusive em períodos de crise política, como a que marcou o primeiro governo Lula. Essa maior exigência acabou acarretando a diminuição da disciplina de todos os partidos, independentemente de seu tipo (centralizado ou descentralizado) e de seu posicionamento em relação ao governo. No entanto, é importante ressaltar que, apesar dos desafios que essa exigência impõe aos parlamentares, as bancadas dos partidos centralizados mostraram maior disciplina que as dos descentralizados, especialmente apoiando os governos que elegeram e, assim, assumindo os ônus e os bônus de seu desempenho perante o eleitorado.

Esses achados mostram a complexidade da dinâmica eleitoral brasileira e, consequentemente, dos incentivos sobre o sistema partidário. Em primeiro lugar, o argumento de que os partidos são organizações débeis, pouco institucionalizadas e nacionalizadas, porque descentralizadas e pouco coesas, não mais se sustenta sem qualificações. Os partidos que participam de forma reiterada e consistente das eleições presidenciais - PT, PSDB, PFL, PSB, PDT, PPS e PC do B - apresentam estratégias que denotam significativa coordenação da ação política quando comparados àqueles que participam delas apenas eventualmente. Assim, os aspectos partidários do comportamento parlamentar não devem ser atribuídos exclusivamente, ou mesmo principalmente, à centralização do processo decisório: da dinâmica das eleições, assim como da arena organizacional, também emergem incentivos no sentido do partidarismo; um partidarismo que, aliás, se firma de forma independente dos recursos que podem ser auferidos do alinhamento aos governos. Em segundo lugar, a pesquisa mostra que a influência das eleições presidenciais sobre a configuração do sistema de partidos não se faz em detrimento da influência do federalismo, possibilitada pelo desenho do sistema eleitoral, o que explica a força eleitoral e o comportamento de partidos como PMDB, PTB, PL e PDS-PP.

(Recebido para publicação em novembro de 2008)

(Reapresentado em maio de 2009)

(Aprovado para publicação em julho de 2009) 


\section{A Influência da Dinâmica Eleitoral sobre o Comportamento dos Partidos...}

\section{NOTAS}

1. Em Venezuela, Filipinas, República Dominicana, Nicarágua, Brasil (1945-1964) e Colômbia (1930, 1942-1946, 1974-1990), de acordo com Shugart e Carey (1992), a média do primeiro colocado é de 49,7\%; a do segundo, 34,9\%. Nos sistemas que exigem segundo turno - Brasil e Chile (1989), Equador (1978-1988), França (1965-1988), Peru (1980-1990), Polônia (1990) -, a média de votos do primeiro colocado é de 39,5\%; a do segundo, $25,1 \%$.

2. No Chile, o Ne para Presidência é 4,0 em 1958; para a assembleia, em 1961,6,4. Nos sistemas que não possuem segundo turno - Venezuela, República Dominicana, Nicarágua, Costa Rica, Brasil (1945-1960) -, a média de candidatos presidenciais efetivos é de 2,5; o Ne na eleição para a assembleia é 3,1. Nos sistemas que exigem o segundo turno - Chile (1989), Equador, Peru, Brasil (1989-1990), França e Portugal -, o número de candidatos presidenciais efetivos é 4,1; o Ne para a assembleia, 5,8 (Shugart e Carey, 1992:180 e 220).

3. O PCB, que disputou as eleições presidenciais e congressuais de 1989 e 1990, era uma das divisões do PCB, criado em 1922. Em 1994, esse partido disputa as eleições legislativas sob a denominação PPS. Surge, nessa ocasião, outro PCB, registrado no Tribunal Superior Eleitoral (TSE) com outro número.

4. A legenda remonta à Arena (Aliança Renovadora Nacional). Em 1982, esse partido disputa as eleições sob a denominação PDS. Em 1993, o PDS incorpora o PDC e altera seu nome para PPR, que disputa as eleições em 1994. Em 1995, o PPR funde-se ao PP, dando origem ao PPB, que disputa as eleições de 1998 e 2002. Em 2003, o PPB muda sua designação para PP (Figueiredo e Limongi, 1999; Melo, 2006).

5. Alemán e Saiegh (2007) discutem a polarização que ocorre nas eleições executivas e legislativas do Chile. Diferentemente da polarização brasileira, a chilena ocorre pela agregação de todos os partidos em duas coalizões: a Concertación por la Democracia e a Alianza por Chile. Os autores explicam essa polarização pelos incentivos à coalescência oriundos da legislação que regula as eleições legislativas e pelo realinhamento do conflito social.

6. É interessante notar que há, na literatura, duas expectativas normativamente contraditórias relativas à volatilidade. Tendo em vista a accountability, conforme os autores citados, o ideal é a volatilidade alta. Quando o foco se desloca para a avaliação da estabilidade dos vínculos entre partidos e eleitores, do grau de enraizamento social dos partidos ou da estabilidade do sistema, a volatilidade baixa se torna o ideal, como mostram os estudos de Mainwaring.

7. A correlação entre a votação obtida pelos partidos nas disputas executivas e congressuais não autoriza a inferência de que o eleitor vinculou seu voto. Evidência nessa direção seria fornecida por pesquisas com o próprio eleitor, como em Carreirão e Kinzo (2004), Rennó (2006). No entanto, é plausível esperar que essa correlação aumente a probabilidade de que a vinculação tenha ocorrido.

8. A emenda foi aprovada em $8 / 3 / 2006$. Em sua redação original, previa-se, no $2^{\circ}$ parágrafo, a aplicação da regra "às eleições que ocorrerão em 2002". O Conselho Federal da Ordem dos Advogados do Brasil apresentou ao Supremo Tribunal Federal uma ação direta de inconstitucionalidade (n-3.685-3) referida a esse parágrafo, alegando a violação do princípio da anterioridade da lei eleitoral e das garantias individuais 


\section{Geralda Luiza de Miranda}

da segurança jurídica e do devido processo legal. Ao afirmarem a procedência da ação de inconstitucionalidade em 22/3/2006, os ministros ressaltaram ainda a impossibilidade empírica de se aplicar a regra às eleições de 2002.

9. Para a Câmara, o PC do B se alia ao PSDB em seis, dois e dois estados em 1990, $1994 \mathrm{e}$ 1998, respectivamente; o número de alianças do PSB com o PSDB, nessas eleições, é de três, seis e seis.

10. A Tabela 1, no Apêndice, traz o número de votações por coalizão (Câmara e Senado); o Quadro 1, os dados das coalizões. Na seleção das votações, utilizei os critérios de Figueiredo e Limongi (1999): excluí as votações unânimes e não válidas. Na verdade, houve quatorze coalizões no período analisado, mas, como nas coalizões 3 e 4 do governo Lula, houve apenas três votações válidas e não unânimes, com encaminhamento do líder no Senado, tratei-as conjuntamente nos diversos testes. A diferença entre elas é a presença, na primeira, do PV. Por fim, importa esclarecer que, na medida em que suponho relação entre o resultado das urnas e o comportamento parlamentar, não foram incluídas, em nenhum dos testes, as votações da coalizão Collor 1, de 1990, realizadas pela representação eleita em 1986.

11. Embora os partidos centralizados tenham sido classificados em três subtipos, o que permite supor comportamentos diferentes também entre eles, tratá-los separadamente na regressão implicaria a inclusão de mais duas dummies, o que prejudica os resultados em uma amostra tão pequena.

12. Como se trata de uma série temporal, as variáveis eficiência e governos impedem também que os efeitos verificados em um período enviesem os resultados dos períodos seguintes.

13. Testei a substituição da variável eficiência pelo percentual de votação alcançado pelas coligações presidenciais efetivas. Tendo alcançado o mesmo resultado, escolhi manter a dummy.

14. No Senado, há um menor número de votações no plenário e maior unanimidade, como pode ser visto na Tabela 1, no Apêndice. As votações não unânimes na Câmara atingem um percentual de $69,8 \%$ do total; no Senado, $54,2 \%$. Além disso, cabe salientar que, quando o partido integra um bloco, os líderes de partido podem encaminhar junto com o líder do bloco (na mesma direção ou em direção diversa) ou se omitir, supostamente aceitando a orientação dada pelo líder do bloco. Como o objetivo, nesta seção, é investigar o posicionamento dos partidos, não computei as votações em que o líder do partido não se manifestou. Com isso, a amostra ficou restrita a trinta partidos no período de 1999 a 2007. Entre os descentralizados, apenas o PMDB possui dados para as seis coalizões do período.

15. Disposição, de acordo com Rosemberg (1968:32), "refere-se não a uma condição ou estado do indivíduo, mas a uma tendência de reagir de certa maneira, em determinadas circunstâncias".

16. O índice é construído da seguinte maneira: 1) calcula-se, para cada votação, o percentual de parlamentares do partido que votam conforme encaminhado pelo líder, tendo-se por referência o total de parlamentares do partido presentes na votação; 2) calcula-se a média dos percentuais, de cada partido, no período de vigência da coalizão. As Tabelas 2 e 3, no Apêndice, trazem o índice de fidelidade dos partidos na Câmara e no Senado, respectivamente. 


\section{A Influência da Dinâmica Eleitoral sobre o Comportamento dos Partidos...}

17. Os encaminhamentos considerados foram: aprovação, rejeição, obstrução e abstenção. Para o cálculo, foram considerados, nas duas Casas, os encaminhamentos do líder do bloco quando o líder do partido se omitiu. A inclusão do encaminhamento do líder do bloco e o de abstenção, não utilizados no cálculo da taxa de coordenação, justifica-se pelo fato de que, nesta seção, o foco está sobre o comportamento do parlamentar, e não na visibilidade que a votação oferece ao partido.

18. No tratamento desse dado, procedi assim: 1) computei o tempo de filiação dos membros dos onze partidos considerando a configuração das bancadas no início de cada uma das treze coalizões; 2) classifiquei os membros em: filiado há menos de oito anos, com oito anos ou mais; 3) calculei o percentual de cada grupo tendo por referência o total de membros do partido.

\section{REFERÊNCIAS BIBLIOGRÁFICAS}

ABRUCIO, Fernando L. (1998), Os Barões da Federação. Os Governadores e a Redemocratização Brasileira. São Paulo, Departamento de Ciência Política da USP/Hucitec.

ALEMÁN, Eduardo e SAIEGH, Sebastián M. (2007), "Legislative Preferences, Political Parties, and Coalition Unity in Chile". Comparative Politics, vol. 39, no 3, pp. 253-272.

AMES, Barry. (2003), Os Entraves da Democracia no Brasil. Rio de Janeiro, Editora FGV.

AMORIM NETO, Octavio e SANTOS, Fabiano. (2003), “O Segredo Ineficiente Revisto: O que Propõem e o que Aprovam os Deputados Brasileiros". DADOS, vol. 46, no 4, pp. 661-698.

AMORIM NETO, Octavio, COX, Gary e MCCUBBINS, Mathew. (2003), “Agenda Power in Brazil's Câmara dos Deputados (1989-98)". World Politics, vol. 55, no 4, pp. 1-46.

BRAGA, Maria do Socorro. (2006), “Dinâmica de Coordenação Eleitoral em Regime Presidencialista e Federativo: Determinantes e Conseqüências das Coligações Partidárias no Brasil", in G. A. D. Soares e L. R. Rennó (orgs.), Reforma Política. Lições da História Recente. Rio de Janeiro, Editora FGV, pp. 229-245.

(2006a), O Processo Partidário-Eleitoral Brasileiro. Padrões de Competição Política (1982-2002). São Paulo, Humanitas/Fapesp.

CARREIRÃO, Yan de S. e KINZO, Maria D'Alva G. (2004), “Partidos Políticos, Preferência Partidária e Decisão Eleitoral no Brasil (1989/2002)”. DADOS, vol. 47, oㅡ 1, pp.131-168.

CARVALHO, Nelson Rojas de. (2003), E no Início eram as Bases. Geografia Política do Voto e Comportamento Legislativo no Brasil. Rio de Janeiro, Revan.

COX, Gary. (1987), The Efficient Secret. Cambridge, Cambridge University Press. e MCCUBBINS, Mathew. (1993), The Legislative Leviathan. Berkeley, University of California Press. 


\section{Geralda Luiza de Miranda}

(1995), "Bonding, Structure, and the Stability of Political Parties: Party Government in the House", in K. A. Shepsle e B. R. Weingast (eds.), Positive Theories of Congressional Institutions. Ann Arbor, The University of Michigan Press, pp. 101-117.

DUVERGER, Maurice. (1994), “Duverger's Law: Forty Years Later", in B. Grofman e A. Lijphart (eds.), Electoral Laws and their Political Consequences. New York, Agathon Press, pp. 69-84.

FIGUEIREDO, Argelina e LIMONGI, Fernando. (1999), Executivo e Legislativo na Nova Ordem Constitucional. Rio de Janeiro, Editora FGV.

(2007), "Instituições Políticas e Governabilidade: Desempenho do Governo e Apoio Legislativo na Democracia Brasileira", in C. R. Melo e M. S. Alcântara (orgs.), A Democracia Brasileira: Balanços e Perspectivas para o Século 21. Belo Horizonte, Ed. UFMG, pp. 148-149.

FIORINA, Morris. (1974), Representatives, Roll Calls, and Constituencies. Lexington, Mass., D.C. Heath.

INÁCIO, Magna M. (2006), Presidencialismo de Coalizão e Sucesso Presidencial na Esfera Legislativa (1990-2004). Tese de doutorado em Ciências Humanas, Faculdade de Filosofia e Ciências Humanas, UFMG, Belo Horizonte.

JONES, Mark. (1995), Electoral Laws and the Survival of Presidential Democracies. Notre Dame, University of Notre Dame Press.

KIEWIET, D. Roderick e MCCUBBINS, Mathew D. (1991), The Logic of Delegation. Congressional Parties and the Appropriations Process. Chicago, University of Chicago Press.

LAMOUNIER, Bolívar e MENEGUELLO, Rachel. (1986), Partidos Políticos e Consolidação Democrática. O Caso Brasileiro. São Paulo, Brasiliense.

LAVAREDA, Antonio. (1991), A Democracia nas Urnas. O Processo Partidário-Eleitoral Brasileiro. Rio de Janeiro, Rio Fundo/IUPERJ.

LIJPHART, Arend. (1991), “Constitutional Choices for New Democracies”. Journal of Democracy, vol. 3, no 2 .

LIMA JÚNIOR, Olavo Brasil de. (1983), Os Partidos Políticos Brasileiros. A Experiência Federal e Regional (1945-1964). Rio de Janeiro, Graal.

. (1993), Democracia e Instituições Políticas no Brasil dos Anos 80. São Paulo, Edições Loyola.

. (1999), "Eleições Presidenciais: Centralidade, Contexto e Implicações". Revista Brasileira de Ciências Sociais, vol. 14, no 40, pp. 11-30.

LINZ, Juan. (1991), "Presidencialismo ou Parlamentarismo: Faz Alguma Diferença?", in B. Lamounier (org.), A Opção Parlamentarista. São Paulo, Sumaré, pp. 61-120.

MAINWARING, Scott. (1999), Sistemas Partidários em Novas Democracias. O Caso do Brasil. Porto Alegre/Rio de Janeiro, Mercado Aberto/Editora FGV.

e JONES, Mark P. (2003), "A Nacionalização dos Partidos e dos Sistemas Partidários. Uma Medição Empírica e sua Aplicação ao Caso das Américas", in J. A. G. Tavares (org.), O Sistema Partidário na Consolidação da Democracia Brasileira. Brasília, Instituto Teotônio Vilela, pp. 102-147. 


\section{A Influência da Dinâmica Eleitoral sobre o Comportamento dos Partidos...}

MARENCO DOS SANTOS, André. (2001), "Sedimentação das Lealdades Partidárias no Brasil: Tendências e Descompassos". Revista Brasileira de Ciências Sociais, vol. 16, no 45 , pp. 69-83.

MELO, Carlos R. (2004), Retirando as Cadeiras do Lugar. Migração Partidária na Câmara dos Deputados (1985-2002). Belo Horizonte, Ed. UFMG.

. (2006), "Sistema Partidário, Presidencialismo e Reforma Política no Brasil", in G. A. D. Soares e L. R. Rennó (orgs.), Reforma Política. Lições da História Recente. Rio de Janeiro, Editora FGV, pp. 157-175.

(2007), "Nem Tanto ao Mar, nem Tanto à Terra. Elementos para uma Análise do Sistema Partidário Brasileiro", in C. R. Melo e M. S. Alcântara (orgs.), A Democracia Brasileira. Balanços e Perspectivas para o Século 21. Belo Horizonte, Ed. UFMG, pp. 268-295.

MELO, Marcus A. (2007), "Hiperconstitucionalização e Qualidade da Democracia: Mito e Realidade”, in C. R. Melo e M. S. Alcântara (orgs.), A Democracia Brasileira. Balançose Perspectivas para o Século 21. Belo Horizonte, Ed. UFMG, pp. 237-265.

NICOLAU, Jairo. (1996), Multipartidarismo e Democracia. Um Estudo sobre o Sistema Partidário Brasileiro (1985-1994). Rio de Janeiro, Editora FGV.

PANEBIANCO, Angelo. (1990), Modelos de Partido. Organización y Poder en los Partidos Políticos. Madrid, Alianza Editorial.

PEREIRA, Carlos e MUELLER, Bernardo. (2003), "Partidos Fracos na Arena Eleitoral e Partidos Fortes na Arena Legislativa: A Conexão Eleitoral no Brasil”. DADOS, vol. 46, no 4, pp. 735-771.

PEREIRA, Carlos e RENNÓ, Lucio R. (2001), “O que É que o Reeleito Tem? Dinâmicas Político-Institucionais Locais e Nacionais nas Eleições de 1998 para a Câmara dos Deputados". DADOS, vol. 44, no 2, pp. 323-362.

POWELL JR., G. Bingham. (2000), Elections as Instruments of Democracy. Majoritarian and Proportional Visions. New Haven/London, Yale University Press.

RENNÓ, Lucio R. (2006), “O Dilema do Rico: Número de Candidatos, Identificação Partidária e Accountability nas Eleições de 2002 para a Câmara dos Deputados", ,in G. A. D. Soares e L. R. Rennó (orgs.), Reforma Política. Lições da História Recente. Rio de Janeiro, Editora FGV, pp. 47-68.

ROSEMBERG, Morris. (1968), A Lógica da Análise do Levantamento de Dados. São Paulo, Cultrix/Edusp.

SAMUELS, David. (2003), Ambition, Federalism, and Legislative Politics in Brazil. Cambridge, Cambridge University Press.

e EATON, Kent. (2002), Presidentialism and, or, and versus Parlamentarism: The State of the Literature and an Agenda for Future Research. Trabalho apresentado na conferência Consequences of Political Institutions in Democracy. Durhan, Duke University, 5-7 de abril. Disponível em http: / / www.quezon.ph/wp-content/uploads / 2006/09/Samuels-Eaton.pdf. Acessado em 2007.

SANTOS, Fabiano. (1997), "Patronagem e Poder de Agenda na Política Brasileira". DADOS, vol. 40, no 3, pp. 465-492. 


\section{Geralda Luiza de Miranda}

(1999), "Instituições Eleitorais e Desempenho do Presidencialismo no Brasil". DADOS, vol. 42, no 1, pp. 111-138.

. (2002), "Partidos e Comissões no Presidencialismo de Coalizão". DADOS, vol. 45. no 2, pp. 237-264.

SARTORI, Giovanni. (1994), Ingeniería Constitucional Comparada. Una Investigación de Estructuras, Incentivos y Resultados. México, Fondo de Cultura Económica.

SHUGART, Matthew e CAREY, John. (1992), Presidents and Assemblies. Constitutional Design and Electoral Dynamics. Cambridge, Cambridge University Press.

SOARES, Gláucio A. D. (1964), “Alianças e Coligações Eleitorais: Notas para uma Teoria". Revista Brasileira de Estudos Políticos, no 17, pp. 95-124. 


\title{
LISTA DE SIGLAS DOS PARTIDOS POLÍTICOS
}

\author{
PC do B - Partido Comunista do Brasil \\ PCB - Partido Comunista Brasileiro \\ PDC - Partido Democrata Cristão \\ PDS - Partido Democrático Social \\ PDT - Partido Democrático Trabalhista \\ PFL - Partido da Frente Liberal \\ PL - Partido Liberal \\ PMDB - Partido do Movimento Democrático Brasileiro \\ PMN - Partido da Mobilização Nacional \\ PP - Partido Progressista \\ PPB - Partido Progressista Brasileiro \\ PPR - Partido Progressista Renovador \\ PPS - Partido Popular Socialista \\ PRB - Partido Republicano Brasileiro \\ PRN - Partido da Reconstrução Nacional \\ PSB - Partido Socialista Brasileiro \\ PSD - Partido Social Democrata \\ PSDB - Partido da Social Democracia Brasileira \\ PSL - Partido Social Liberal \\ PST - Partido Social Trabalhista \\ PSTU - Partido Socialista dos Trabalhadores Unificado \\ PT - Partido dos Trabalhadores \\ PTB - Partido Trabalhista Brasileiro \\ PV - Partido Verde
}




\section{APÊNDICE}

Tabela 1

Universo de Votações Nominais - Câmara dos Deputados e Senado Federal (1991-2007)

\begin{tabular}{l|c|c|c|c|c|c}
\hline \multirow{2}{*}{ Coalizão } & \multicolumn{2}{|c|}{ Total (A) } & \multicolumn{2}{c|}{$\begin{array}{c}\text { Unânimes/Não } \\
\text { Válidas (B) }\end{array}$} & \multicolumn{2}{c}{ Total (A-B) } \\
\cline { 2 - 7 } & Câmara & Senado & Câmara & Senado & Câmara & Senado \\
\hline Collor 2 & 110 & $\ldots$ & 77 & $\ldots$ & 33 & $\ldots$ \\
Collor 3 & 31 & $\ldots$ & 21 & $\ldots$ & 10 & $\ldots$ \\
Itamar 1 & 73 & $\ldots$ & 45 & $\ldots$ & 28 & $\ldots$ \\
Itamar 2 & 15 & $\ldots$ & 11 & $\ldots$ & 4 & $\ldots$ \\
Itamar 3 & 21 & $\ldots$ & 8 & $\ldots$ & 13 & $\ldots$ \\
Fernando Henrique I 1 & 163 & $\ldots$ & 133 & $\ldots$ & 30 & $\ldots$ \\
Fernando Henrique I 2 & 360 & $\ldots$ & 292 & $\ldots$ & 68 & $\ldots$ \\
Fernando Henrique II 1 & 428 & 231 & 266 & 90 & 162 & 141 \\
Fernando Henrique II 2 & 36 & 53 & 20 & 34 & 16 & 19 \\
Lula 1 & 154 & 84 & 91 & 56 & 63 & 28 \\
Lula 2 & 114 & 47 & 41 & 25 & 73 & 22 \\
Lula 3 & 20 & 13 & 12 & 11 & 8 & 2 \\
Lula 4 & 29 & 3 & 11 & 2 & 18 & 1 \\
Lula 5 & 126 & 69 & 59 & 53 & 67 & 16 \\
\hline Total & $\mathbf{1 . 6 8 0}$ & 500 & $\mathbf{1 . 0 8 7}$ & $\mathbf{2 7 1}$ & 593 & $\mathbf{2 2 9}$ \\
\hline
\end{tabular}

Fontes: Bancos de dados legislativos da Câmara dos Deputados (1989-2007) e do Senado Federal (1988-2007), cedidos por Figueiredo e Limongi; diários e listas de votações nominais do Senado Federal.

Nota: * Para o Senado, apenas votações unânimes. 
A Influência da Dinâmica Eleitoral sobre o Comportamento dos Partidos...

Tabela 2

Índice de Fidelidade na Câmara por Partido e por Coalizão (1991-2007)

\begin{tabular}{|c|c|c|c|c|c|c|c|c|c|c|c|c|c|}
\hline \multirow[t]{2}{*}{$\begin{array}{l}\text { Coalizão/ } \\
\text { Partido }\end{array}$} & \multicolumn{2}{|c|}{ Collor } & \multicolumn{3}{|c|}{ Itamar } & \multicolumn{2}{|c|}{$\begin{array}{c}\text { Fernando } \\
\text { Henrique I } \\
\end{array}$} & \multicolumn{2}{|c|}{$\begin{array}{c}\text { Fernando } \\
\text { Henrique II }\end{array}$} & \multicolumn{4}{|c|}{ Lula } \\
\hline & 2 & 3 & 1 & 2 & 3 & 1 & 2 & 1 & 2 & 1 & 2 & 3 e 4 & 5 \\
\hline PT & 97,9 & 97,3 & 97,3 & 95,7 & 97,7 & 98 & 98,4 & 98,8 & 98,3 & 96,0 & 94,5 & 88,1 & 94,5 \\
\hline PC do B & 97,2 & 98,8 & 99,1 & 94,3 & 91,7 & 97,8 & 98,9 & 99,2 & 98,3 & 98,3 & 98,0 & 99,2 & 92,8 \\
\hline PSB & 94,0 & 95,5 & 91,5 & 93,8 & 90,0 & 82,8 & 94,0 & 97,3 & 93,5 & 96,0 & 95,4 & 86,1 & 86,5 \\
\hline PDT & 91,0 & 92,0 & 87,1 & 93,5 & 86,9 & 88,2 & 93,7 & 95,1 & 91,6 & 90,4 & 84,9 & 84,4 & 91,7 \\
\hline PPS & 97,5 & 93,8 & 100 & 100 & 75,0 & 93,5 & 90,9 & 88,6 & 69,3 & 97,4 & 93,0 & 81,1 & 94,3 \\
\hline PSDB & 88,5 & 89,8 & 88,9 & 76,5 & 87,3 & 90,9 & 92,3 & 96,0 & 94,6 & 78,3 & 85,0 & 89,6 & 93,3 \\
\hline PDMB & 87,5 & 87,6 & 88,1 & 94,0 & 90,1 & 83,0 & 80,5 & 85,7 & 88,1 & 92,0 & 80,8 & 74,4 & 81,6 \\
\hline PL & 90,3 & 92,1 & 85,4 & 94,4 & 83,9 & 88,9 & 73,1 & 76,8 & 73,8 & 96,7 & 94,1 & 85,7 & 87,1 \\
\hline РTB & 80,5 & 90,8 & 82,5 & 86,9 & 80,8 & 88,0 & 87,6 & 86,7 & 83,7 & 91,7 & 90,8 & 80,5 & 86,8 \\
\hline PDS-PP & 87,8 & 85,9 & 82,3 & 93,9 & 91,2 & 89,5 & 81,1 & 90,6 & 89,0 & 86,7 & 82,2 & 79,7 & 82,8 \\
\hline PFL & 86,4 & 95,1 & 84,0 & 89,7 & 89,4 & 93,0 & 94,0 & 95,6 & 93,9 & 73,5 & 84,8 & 86,9 & 90,4 \\
\hline
\end{tabular}

Fonte: Banco de dados legislativos da Câmara dos Deputados (1989-2007), cedido por Figueiredo e Limongi.

Tabela 3

Índice de Fidelidade no Senado por Partido e por Coalizão

(1999-2007)

\begin{tabular}{l|c|c|c|c|c|c}
\hline \multirow{2}{*}{$\begin{array}{l}\text { Coalizão/ } \\
\text { Partido }\end{array}$} & Fernando Henrique II & \multicolumn{5}{|c}{ Lula } \\
\cline { 2 - 7 } & $\mathbf{1}$ & $\mathbf{2}$ & $\mathbf{1}$ & $\mathbf{2}$ & $\mathbf{3}$ e 4 & $\mathbf{5}$ \\
\hline PT & 93,6 & 79,3 & 88,3 & 90,8 & 100 & 89,2 \\
PSB & 97,5 & 86,4 & 91,7 & 85,4 & 100 & 84,7 \\
PDT & 84,3 & 91,7 & 82,1 & 84,6 & & 83,3 \\
PPS & 99,2 & 100 & 100 & 100 & & \\
PSDB & 89,2 & 92,4 & 83,0 & 88,0 & 91,7 & 77,4 \\
PDMB & 82,8 & 80,6 & 81,9 & 83,6 & 93,7 & 73,8 \\
PL & & & 100 & 87,5 & 100 & 84,7 \\
PTB & 83,3 & 90,1 & 76,6 & 98,1 & 100 & 100 \\
PDS-PP & 92,3 & 95,8 & & & & \\
PFL & 89,6 & 91,8 & 79,3 & 78,5 & 75,6 & 91,5 \\
\hline
\end{tabular}

Fontes: Banco de dados legislativos do Senado Federal (1989-2007), cedido por Figueiredo e Limongi; diários e listas de votações nominais do Senado Federal. 


\begin{tabular}{|c|c|c|c|c|}
\hline & Coali & $\begin{array}{l}\text { Quadro } 1 \\
\text { jes Governa } \\
\text { 1991-2007) }\end{array}$ & vas & \\
\hline Nome & Número & $\begin{array}{c}\text { Partido } \\
\text { Presidente }\end{array}$ & $\begin{array}{c}\text { Partidos } \\
\text { Integrantes }\end{array}$ & Período \\
\hline Collor 2 & 1 & PRN & PRN-PDS-PFL & $\begin{array}{c}1^{\circ} / 2 / 1991 \text { a } \\
14 / 4 / 1992\end{array}$ \\
\hline Collor 3 & 2 & PRN & PDS-PTB-PL-PFL & $\begin{array}{c}15 / 4 / 1992 \text { a } \\
30 / 9 / 1992\end{array}$ \\
\hline Itamar 1 & 3 & S/partido & $\begin{array}{c}\text { PSDB-PTB-PMD } \\
\text { B-PSB-PFL }\end{array}$ & $\begin{array}{c}1^{\circ} / 10 / 1992 \mathrm{a} \\
30 / 8 / 1993 \\
\end{array}$ \\
\hline Itamar 2 & 4 & S/partido & $\begin{array}{c}\text { PSDB-PTB- } \\
\text { PMDB-PP-PFL }\end{array}$ & $\begin{array}{c}31 / 8 / 1993 \text { a } \\
24 / 1 / 1994\end{array}$ \\
\hline Itamar 3 & 5 & S/partido & $\begin{array}{c}\text { PSDB-PP-PMDB- } \\
\text { PFL }\end{array}$ & $\begin{array}{l}25 / 1 / 1994 \mathrm{a} \\
31 / 12 / 1994 \\
\end{array}$ \\
\hline Fernando Henrique I 1 & 6 & PSDB & $\begin{array}{l}\text { PSDB-PFL- } \\
\text { PMDB-PTB }\end{array}$ & $\begin{array}{c}19 / 1 / 1995 \text { a } \\
25 / 4 / 1996\end{array}$ \\
\hline Fernando Henrique I 2 & 7 & PSDB & $\begin{array}{c}\text { PSDB-PFL- } \\
\text { PMDB-PTB-PPB }\end{array}$ & $\begin{array}{c}26 / 4 / 1996 \text { a } \\
31 / 12 / 1998 \\
\end{array}$ \\
\hline Fernando Henrique II 1 & 8 & PSDB & $\begin{array}{l}\text { PSDB-PMDB- } \\
\text { PPB-PTB-PFL }\end{array}$ & $\begin{array}{c}1^{\circ} / 1 / 1999 a \\
5 / 3 / 2002\end{array}$ \\
\hline Fernando Henrique II 2 & 9 & PSDB & $\begin{array}{c}\text { PMDB-PSDB- } \\
\text { PPB }\end{array}$ & $\begin{array}{l}6 / 3 / 2002 a \\
31 / 12 / 2002 \\
\end{array}$ \\
\hline Lula 1 & 10 & PT & $\begin{array}{c}\text { PT-PL-PC do } \\
\text { B-PSB-PTB-PDT- } \\
\text { PPS-PV }\end{array}$ & $\begin{array}{c}1^{\circ} / 1 / 2003 \mathrm{a} \\
22 / 1 / 2004\end{array}$ \\
\hline Lula 2 & 11 & $\mathrm{PT}$ & $\begin{array}{c}\text { PT-PL-PC do } \\
\text { B-PSB-PTB-PPS- } \\
\text { PV-PMDB }\end{array}$ & $\begin{array}{c}23 / 1 / 2004 \mathrm{a} \\
31 / 1 / 2005\end{array}$ \\
\hline Lula 3 & 12 & PT & $\begin{array}{l}\text { PT-PL-PC do } \\
\text { B-PSB-PTB- } \\
\text { PMDB-PV }\end{array}$ & $\begin{array}{c}1^{\circ} / 2 / 2005 a \\
19 / 5 / 2005\end{array}$ \\
\hline Lula 4 & 13 & $\mathrm{PT}$ & $\begin{array}{l}\text { PT-PL-PC do } \\
\text { B-PSB-PTB- } \\
\text { PMDB }\end{array}$ & $\begin{array}{c}20 / 5 / 2005 \text { a } \\
22 / 7 / 2005\end{array}$ \\
\hline Lula 5 & 14 & PT & $\begin{array}{c}\text { PT-PL-PC do } \\
\text { B-PSB-PTB-PP- } \\
\text { PMDB }\end{array}$ & $\begin{array}{c}23 / 7 / 2005 a \\
31 / 1 / 2007\end{array}$ \\
\hline
\end{tabular}

Fonte: Adaptado de Figueiredo e Limongi (2007). 


\section{ABSTRACT \\ The Impact of Electoral Dynamics on Partisan Political Behavior in the Brazilian Chamber of Deputies and National Senate}

This article discusses the impact of electoral dynamics on partisan political behavior in the Brazilian Congressional arena. Based on an analysis of voting and electoral alliances, the author shows that Presidential elections became efficient and influenced the parties' performance and alignments in Congressional disputes. She then proceeds to argue that repeat contestants in Presidential races behave more coherently and in a more disciplined way in the Congressional arena in order to maximize their party's electoral value, which is not expected of one-time Presidential contestants. The findings show that the partisan approach underlying the behavior of party leadership and delegations in the Brazilian Congress is explained by the electoral and organizational dynamics, and not only by centralization of the decision-making process.

Key words: Chamber of Deputies; National Senate; Brazilian elections; electoral alliances; Congressional behavior

\section{RÉSUMÉ \\ L'Influence de la Dynamique Électorale sur la Conduite des Partis à la Chambre des Députés et au Sénat brésilien}

Dans cet article, on examine l'influence de la dynamique électorale à l'égard de la conduite des partis sur la scène parlementaire brésilienne. D'après l'analyse des séances de vote et des coalitions électorales, on voit que les élections présidentielles sont devenues efficaces et influencent l'action et les associations de partis lors des disputes au Congrès. On peut donc penser que les candidats qui se présentent le plus souvent aux élections présidentielles ont une conduite plus cohérente et mieux disciplinée, afin de tirer profit de la tête de liste de leur parti, ce qu'on n'attend pas des candidats éventuels. Les résultats montrent que l'esprit partisan qui guide le comportement des dirigeants et des groupes parlementaires s'explique par la dynamique électorale et organisationnelle et pas seulement par la centralisation du processus de décision.

Mots-clé: Chambre des Députés; Sénat Fédéral; élections brésiliennes; coalitions électorales; comportement parlementaire 